\title{
Direct Releases to the Surface and Associated Complementary Cumulative Distribution Functions in the 1996 Performance Assessment for the Waste Isolation Pilot Plant: Cuttings, Cavings and Spallings
}

\author{
J.W. Berglund, a J.W. Garner, ${ }^{\text {b J.C. Helton, }}{ }^{c}$ J.D. Johnson, ${ }^{\text {d L.N. Smith }}$ \\ a New Mexico Engineering Research Institute, Albuquerque, NM 87106 USA; bPiru Associates, \\ Albuquerque, NM 87106 USA; 'Department of Mathematics; Arizona State University, Tempe, AZ 85287 \\ USA; dGRAM. Inc., Albuquerque, NM 87112 USA; 'Comforce, Albuquerque. NM 87110 USA
}

\begin{abstract}
The following topics related to the treatment of cuttings, cavings and spallings releases to the surface environment in the 1996 performance assessment for the Waste Isolation Pilot Plant (WIPP) are presented: (i) mathematical description of models, (ii) uncertainty and sensitivity analysis results arising from subjective (i.e., epistemic) uncertainty for individual releases, (iii) construction of complementary cumulative distribution functions (CCDFs) arising from stochastic (i.e., aleatory) uncertainty, and (iv) uncertainty and sensitivity analysis results for CCDFs. The presented results indicate that direct releases due to cuttings, cavings and spallings do not constitute a serious threat to the effectiveness of the WIPP as a disposal facility for transuranic waste. Even when the effects of uncertain analysis inputs are taken into account, the CCDFs for cuttings, cavings and spallings releases fall substantially to the left of the boundary line specified in the U.S. Environmental Protection Agency's standard for the geologic disposal of radioactive waste (40 CFR 191, 40 CFR 194).
\end{abstract}

Key Words: Aleatory uncertainty, cavings, compliance certification application, cuttings, epistemic uncertainty, Latin hypercube sampling. Monte Carlo, performance assessment, radioactive waste, risk, spallings, stochastic uncertainty. subjective uncertainty, transuranic waste, Waste Isolation Pilot Plant, 40 CFR 191, 40 CFR 194.

Please send page proof to:

Jon C. Helton

Department 6848. MS 0779

Sandia National Laboratories

Albuquerque. NM 87185-0779. USA

Phone: 505-284-4808

Fax: 505-844-2348

email: jchelto@sandia.gov 


\section{DISCLAIMER}

This report was prepared as an account of work sponsored by an agency of the United States Government. Neither the United States Government nor any agency thereof, nor any of their employees, make any warranty, express or implied, or assumes any legal liability or responsibility for the accuracy, completeness, or usefulness of any information, apparatus, product, or process disclosed, or represents that its use would not infringe privately owned rights. Reference herein to any specific commercial product, process, or service by trade name, trademark, manufacturer, or otherwise does not necessarily constitute or imply its endorsement, recommendation, or favoring by the United States Government or any agency thereof. The views and opinions of authors expressed herein do not necessarily state or reflect those of the United States Government or any agency thereof. 


\section{DISCLAIMER}

Portions of this document may be illegible in electronic image products. Images are produced from the best available original document. 


\section{Introduction}

The Waste Isolation Pilot Plant (WIPP) is under development by the U.S. Department of Energy (DOE) for the geologic disposal of transuranic waste. This article describes the modeling of solid releases to the surface (i.e., the accessible environment) at the time of an inadvertent drilling intrusion into the waste panels associated with the WIPP and the construction of associated complementary cumulative distribution functions (CCDFs) for comparison with U.S. Environmental Protection Agency's (EPA's) standard for the geologic disposal of radioactive waste. ${ }^{1-4}$ The presented models and results constitute part of the 1996 performance assessment (PA) for the WIPP and support a compliance certification application (CCA) by the DOE to the EPA for the certification of the WIPP for the disposal of transuranic waste. ${ }^{5}$

Three separate release modes, cuttings, cavings and spallings, are believed to determine the quantity of solid waste brought to the ground surface as the result of a drilling intrusion through a waste panel, where cuttings designates the waste contained in the cylindrical volume created by the cutting action of the drill bit passing through the waste, cavings designates the waste that erodes from the borehole in response to the upward-flowing drilling fluid within the borehole, and spallings designates the waste brought to the surface by waste-generated gas venting to the lower-pressure borehole. Multiplication of the volumes of material associated with these release modes by appropriate radionuclide concentrations then produces radionuclide releases to the accessible environment (i.e., the land surface) due to cuttings, cavings and spallings.

At a conceptual level, the 1996 WIPP PA is underlain by three entities (EN1, EN2, EN3): EN1, a probabilistic characterization of the likelihood of different futures occurring at the WIPP site over the next $10,000 \mathrm{yr}$; EN2, a procedure for estimating the radionuclide releases to the accessible environment associated with each of the possible futures that could occur at the WIPP site over the next $10,000 \mathrm{yr}$; and EN3, a probabilistic characterization of the uncertainty in the parameters used in the definitions of EN1 and EN2 (Sect. 2, Ref. 6). All three of these entities play a role in the direct release results presented in this article. In particular, the following topics are considered: (i) models for cuttings, cavings and spallings releases, which constitute part of EN2 (Sect. 4, Ref. 6); (ii) construction of CCDFs for direct releases to the surface, which involves the probability space $\left(\mathrm{S}_{s t}, \&_{s t}, p_{s t}\right)$ for stochastic uncertainty associated with EN1 (Sect. 3, Ref. 6; Ref. 7); and (iii) uncertainty and sensitivity analysis to assess the implications of uncertain analysis inputs, which involves the probability space $\left(\mathrm{S}_{s u}, \&_{s u}, p_{s u}\right)$ for subjective uncertainty associated with EN3 (Sect. 5, Ref. 6; Ref. 8).

When viewed formally, EN2 is defined by a function $f$ of the form

$$
f\left(\mathbf{x}_{s t}\right)=f_{C}\left(\mathbf{x}_{s t}\right)+f_{S P}\left[\mathbf{x}_{s t}, f_{B}\left(\mathbf{x}_{s t}\right)\right]+f_{D B R}\left\{\mathbf{x}_{s t}, f_{S P}\left[\mathbf{x}_{s t}, f_{B}\left(\mathbf{x}_{s t}\right)\right], f_{B}\left(\mathbf{x}_{s t}\right)\right\}
$$




$$
\begin{aligned}
& \because f_{M B} Q \mathbf{x}_{s t}, f_{B} \mathbf{x}_{s t} \Xi f_{D L} \mathbf{x}_{s t}, f_{B} \mathbf{x}_{s t} \because f_{S}\left(\mathbf{x}_{s t}, f_{B} \mathbf{x}_{s t}\right. \\
& +f_{S-T}\left\{\mathbf{x}_{s t, 0}, f_{S-F}\left(\mathbf{x}_{s t, 0}\right), f_{N-P}\left[\mathbf{x}_{s t}, f_{B}\left(\mathbf{x}_{s t}\right)\right]\right\},
\end{aligned}
$$

where $\mathbf{x}_{s t} \sim$ particular future under consideration, $\mathbf{x}_{s t, 0} \sim$ future involving no drilling intrusions but a mining event at the same time $t_{\min }$ as in $\mathbf{x}_{s t}, f_{C}\left(\mathbf{x}_{s t}\right) \sim$ cuttings and cavings release to accessible environment for $\mathbf{x}_{s t}$ calculated with CUTTINGS_S, $f_{B}\left(\mathbf{x}_{s t}\right) \sim$ two-phase flow results calculated for $\mathbf{x}_{s t}$ with BRAGFLO (in practice, $f_{B}\left(\mathbf{x}_{s t}\right)$ is a vector containing a large amount of information), $f_{S P}\left[\mathbf{x}_{s t}, f_{B}\left(\mathbf{x}_{s t}\right)\right] \sim$ spallings release to accessible environment for $\mathbf{x}_{s t}$ calculated with the spallings model contained in CUTTINGS_S (this calculation requires BRAGFLO results (i.e., $\left.f_{B}\left(\mathbf{x}_{s t}\right)\right)$ as input), $f_{D B R}\left\{\mathbf{x}_{s t}, f_{S P}\left[\mathbf{x}_{s t}, f_{B}\left(\mathbf{x}_{s t}\right)\right], f_{B}\left(\mathbf{x}_{s t}\right)\right\} \sim$ direct brine release to accessible environment for $\mathbf{x}_{s t}$ calculated with a modified version of BRAGFLO designated BRAGFLO_DBR (this calculation requires spallings results obtained from CUTTINGS_S (i.e., $f_{S P}\left[\mathbf{x}_{s t}, f_{B}\left(\mathbf{x}_{s t}\right)\right]$ ) and BRAGFLO results (i.e., $f_{B}\left(\mathbf{x}_{s t}\right)$ ) as input), $f_{M B}\left[\mathbf{x}_{s t}, f_{B}\left(\mathbf{x}_{s t}\right)\right] \sim$ release through anhydrite marker beds to accessible environment for $\mathbf{x}_{s t}$ calculated with NUTS (this calculation requires BRAGFLO results (i.e., $f_{B}\left(\mathbf{x}_{s t}\right)$ ) as input), $f_{D L}\left[\mathbf{x}_{s t}, f_{B}\left(\mathbf{x}_{s t}\right)\right] \sim$ release through Dewey Lake Red Beds to accessible environment for $\mathbf{x}_{S t}$ calculated with NUTS (this calculation requires BRAGFLO results (i.e., $\left.f_{B}\left(\mathbf{x}_{s t}\right)\right)$ as input), $f_{S}\left[\mathbf{x}_{s t}, f_{B}\left(\mathbf{x}_{s t}\right)\right] \sim$ release to land surface due to brine flow up a plugged borehole for $\mathbf{x}_{s t}$ calculated with NUTS or PANEL (this calculation requires BRAGFLO results (i.e., $f_{B}\left(\mathbf{x}_{s t}\right)$ ) as input), $f_{S-F}\left(\mathbf{x}_{s t, 0}\right) \sim$ Culebra flow field calculated for $\mathbf{x}_{s t, 0}$ with SECOFL2D, $f_{N-P}\left[\mathbf{x}_{s t}, f_{B}\left(\mathbf{x}_{s t}\right)\right] \sim$ release to Culebra for $\mathbf{x}_{s t}$ calculated with NUTS or PANEL as appropriate (this calculation requires BRAGFLO results (i.e., $f_{B}\left(\mathbf{x}_{s t}\right)$ ) as input), $f_{S-T}\left\{\mathbf{x}_{s t, 0}, f_{S-F}\left(\mathbf{x}_{s t, 0}\right), f_{N-P}\left[\mathbf{x}_{s t}, f_{B}\left(\mathbf{x}_{s t}\right)\right]\right\} \sim$ groundwater transport release through Culebra to accessible environment calculated with SECOTP2D (this calculation requires SECOFL2D results (i.e., $f_{S-F}\left(\mathbf{x}_{s t, 0}\right)$ ) and NUTS or PANEL results (i.e., $f_{N-P}\left[\mathbf{x}_{s t}, f_{B}\left(\mathbf{x}_{S t}\right)\right]$ ) as input; $\mathbf{x}_{s t, 0}$ is used as an argument to $f_{S-T}$ because drilling intrusions are assumed to cause no perturbations to the flow field in the Culebra) (Sect. 4, Ref. 6).

The function $f_{C}$ in Eq. (1) corresponds to the model used for radionuclide releases due to cuttings and cavings in the 1996 WIPP PA, with the computational evaluation of this model being carried out by the CUTTINGS_S program (Fig. 2, Table 2, Ref. 6). Similarly, the function $f_{S P}$ in Eq. (1) corresponds to the model used for radionuclide releases due to spallings, with the computational evaluation of this model also being carried out by the CUTTINGS_S program. Actually, CUTTINGS_S estimates the volumes of solid material removed due to cuttings, cavings and spallings, with the final multiplication of the appropriate radionuclide concentrations taking place within the CCDF construction process. The models used for the solid releases associated with cuttings, cavings and spallings are described in Sects. 2-3 and 6-8. The mathematical formulations of the other functions appearing in Eq. (1) (i.e., $f_{B}, f_{D B R}, f_{M B}, f_{D L}, f_{S}, f_{S-T}, f_{S-F}, f_{N-P}$ ) are described in other articles. $9-12$ 
At a conceptual level, evaluation of the CCDFs for cuttings, cavings and spallings releases to the surface involves evaluation of the following integrals (Sect. 4, Ref. 6):

$$
\begin{aligned}
& \operatorname{prob}_{C}(\operatorname{Rel}>R)=\int_{S_{s t}} \delta_{R}\left[f_{C}\left(\mathbf{x}_{s t}\right)\right] d_{s t}\left(\mathbf{x}_{s t}\right) d V_{s t} \\
& \operatorname{prob}_{S P}(\operatorname{Rel}>R)=\int_{S_{s t}} \delta_{R}\left\{f_{S P}\left[\mathbf{x}_{s t}, f_{B}\left(\mathbf{x}_{s t}\right)\right]\right\} d_{s t}\left(\mathbf{x}_{s t}\right) d V_{s t}
\end{aligned}
$$

where $\delta_{R}\left[f_{C}\left(\mathbf{x}_{s t}\right)\right]=1$ if $f_{C}\left(\mathbf{x}_{s t}\right)>R$ and 0 if $f_{C}\left(\mathbf{x}_{s t}\right) \leq R, \delta_{R}\left\{f_{S P}\left[\mathbf{x}_{s t}, f_{B}\left(\mathbf{x}_{s t}\right)\right]\right\}$ is defined similarly, $d_{s t}$ is the density function associated with the probability space $\left(\mathrm{S}_{s t}, \&_{s t}, p_{s t}\right)$ for stochastic uncertainty, prob $(R e l>R)$ is the probability that a cuttings and cavings release greater than size $R$ will occur, and $\operatorname{prob}_{S P}(\operatorname{Rel}>R)$ is defined similarly for spallings releases. Typically, $R$ is expressed in the normalized units defined by the EPA (Eq. (1), Ref. 6 , although other possibilities exist (e.g., $\mathrm{m}^{3}$ when $f_{C}$ and $f_{S P}$ are used to represent volume of material released). In practice, the two preceding integrals are too complex to allow closed-form evaluations. As a result, the 1996 WIPP PA uses the Monte Carlo procedure indicated below to estimate these integrals (Sect. 4, Ref. 6; Sects. 10, 11, Ref. 7):

$$
\begin{aligned}
& \operatorname{prob}_{C}(\operatorname{Rel}>R) \doteq \sum_{i=1}^{n S} \delta_{R}\left[f_{C}\left(\mathbf{x}_{s t, i}\right)\right] / n S \\
& \operatorname{prob}_{S P}(\operatorname{Rel}>R) \doteq \sum_{i=1}^{n S} \delta_{R}\left\{f_{S P}\left[\mathbf{x}_{s t, i}, f_{B}\left(\mathbf{x}_{s t, i}\right)\right]\right\} / n S,
\end{aligned}
$$

where the $\mathrm{x}_{s t, i}, i=1,2, \ldots, n S=10,000$, correspond to a random sample of size $n S=10,000$ from the sample space $\mathrm{S}_{s t}$ associated with the probability space $\left(\mathrm{S}_{s t}, \& \quad s t, p_{s t}\right)$ for stochastic uncertainty. The evaluation of the preceding approximations to produce CCDFs for cuttings, cavings and spallings releases are discussed in Sects. 5 and 10. The construction of CCDFs for the other release modes is discussed in other articles. ${ }^{10-13}$

When the effects of imprecisely known analysis inputs are included, the representations for the cuttings, cavings and spallings releases become $f_{C}\left(\mathbf{x}_{s t}, \mathbf{x}_{s u}\right)$ and $f_{S P}\left[\mathbf{x}_{s t}, \mathbf{x}_{s u}, f_{B}\left(\mathbf{x}_{s t}, \mathbf{x}_{s u}\right)\right]$, where $\mathbf{x}_{s u}$ is an element of the sample space $\mathrm{S}_{s u}$ associated with the probability space $\left(\mathrm{S}_{s u}, \& \quad s u, p_{s u}\right)$ for subjective uncertainty (Sect. 5, Ref. 6; Ref. 8). The possible values for $\mathbf{x}_{s u}$ lead to distributions of cuttings, cavings and spallings releases for both specific futures $\mathbf{x}_{s t}$ and also for the CCDFs that result from integrating over all possible values for $\mathbf{x}_{s t}$. In the 1996 WIPP PA, these distributions are approximated by using Latin hypercube sampling ${ }^{14}$ to generate a mapping from $\mathrm{S}_{s u}$ to analysis outcomes of interest (Sect. 5, Ref. 6; Sect. 8, Ref. 8). The generation and presentation of this mapping is usually referred to as uncertainty analysis. Once generated, this mapping can be explored with sensitivity analysis 
techniques based on examination of scatterplots, regression analysis, and correlation analysis (Sect. 3.5, Ref. 15). Uncertainty and sensitivity analysis results for the cuttings, cavings and spallings releases are presented in Sects. 4-5 and 9-10. Uncertainty and sensitivity analysis results for the other release modes are available in other articles. ${ }^{10-13,16,17}$

This article is based on material contained in Sect. 4.5, Sect. 4.6 and Chapt. 9 of Ref. 18 .

\section{Cuttings}

The uncompacted volume of cuttings removed and transported to the surface in the drilling mud, $V_{c u t}$ is given by

$$
V_{c u t}=A H_{i}=\pi D^{2} H_{i} / 4,
$$

where $H_{i}$ is the initial (i.e., uncompacted) repository height (m), $A$ is the drill bit area $\left(\mathrm{m}^{2}\right)$, and $D$ is the drill bit diameter (m). In the 1996 WIPP PA, $D=12.25 \mathrm{in} .=0.31115 \mathrm{~m}$ and $H_{i}=3.96 \mathrm{~m}$ (Sect. 7.0 , Ref. 19). For drilling intrusions through RH-TRU waste, $H_{i}=0.509 \mathrm{~m}$ is used. ${ }^{20}$ The size of the cuttings release is independent of the conditions that exist in the repository at the time of a drilling intrusion, with the result that the cuttings volume $V_{c u t}$ is a lower bound on the quantity of material removed by a drilling intrusion.

\section{Cavings (adapted from Sect. 3.5 of Ref. 21)}

The cavings component of the direct surface release is caused by the shearing action of the drilling fluid (mud) on the waste as the mud flows up the borehole annulus. As is the case for the cuttings release, the cavings release is assumed to be independent of the conditions that exist in the repository at the time of a drilling intrusion.

The final diameter of the borehole will depend on the diameter of the drill bit and on the extent to which the actual borehole diameter exceeds the drill bit diameter. Although a number of factors affect erosion within a borehole, ${ }^{22}$ the most important factor is believed to be the fluid shear stress on the borehole wall (i.e., the shearing force per unit area, $\left(\mathrm{kg} \mathrm{m} / \mathrm{s}^{2} / \mathrm{m}^{2}\right)$ resulting from circulating drilling fluids. ${ }^{23,} 24$ As a result, the 1996 WIPP PA estimates cavings removal with a model based on the effect of shear stress on the borehole diameter. In particular, the borehole diameter is assumed to grow until the shear stress on the borehole wall is equal to the shear strength of the waste (i.e., the limiting shear stress below which the erosion of the waste ceases).

The final eroded diameter $D_{f}(\mathrm{~m})$ of the borehole through the waste determines the volume $V\left(\mathrm{~m}^{3}\right)$ of uncompacted waste that will be removed to the surface by circulating drilling fluid. Specifically,

$$
V=V_{c u t}+V_{c a v}=\pi D_{f}^{2} H_{i} / 4
$$


where $V_{c a v}$ is the volume $\left(\mathrm{m}^{3}\right)$ of waste removed as cavings.

Most borehole erosion is believed to occur in the vicinity of the drill collar (Fig. 1) (Ref. 26, Letters 1a and 1b, App. A). An important determinant of the extent of this erosion is whether the flow of the drilling fluid in the vicinity of the collar is laminar or turbulent. The 1996 WIPP PA uses Reynolds numbers to distinguish between the occurrence of laminar flow and turbulent flow. The Reynolds number is the ratio between inertial and viscous (i.e., shear) forces in a fluid and can be expressed as

$$
R_{e}=\rho_{f}\|\mathbf{v}\| D_{e} / \eta
$$

where $R_{e}$ is the Reynolds number (dimensionless), $\rho_{f}$ is the fluid density $\left(\mathrm{kg} \mathrm{m}^{-3}\right), D_{e}$ is the equivalent diameter (m), $\mathbf{v}$ is the fluid velocity $\left(\mathrm{m} \mathrm{s}^{-1}\right)$, and $\eta$ is the fluid viscosity $\left(\mathrm{kg} \mathrm{m}^{-1} \mathrm{~s}^{-1}\right)$.

Typically, $\rho, \mathbf{v}$ and $\eta$ are averages over a control volume with an equivalent diameter of $D_{e}$. In the 1996 WIPP PA, $\rho_{f}=1.21 \times 10^{3} \mathrm{~kg} \mathrm{~m}^{-3}$ (Sect. 7.0, Ref. 19), $\|\mathbf{V}\|=0.7089 \mathrm{~m} \mathrm{~s}^{-1}$ (based on 40 gallons $/$ min per inch of drill diameter, Sect. 2.3, Ref. 27), and $D_{e}=2\left(R-R_{i}\right)$ as shown in Fig. 1. The diameter of the drill collar (i.e., $2 R_{i}$ in Fig. 4.5.1) is 8.0 in $=0.2032 \mathrm{~m}$ (Sect. 7.0, Ref. 19). The determination of $\eta$ is discussed below. Reynolds numbers less than 2100 are assumed to be associated with laminar flow, while Reynolds numbers greater than 2100 are assumed to be associated with turbulent flow. ${ }^{28}$

Drilling fluids are non-Newtonian fluids, which means that the viscosity $\eta$ is a function of the shear rate within the fluid (i.e., the rate at which the fluid velocity changes normal to the flow direction, $((\mathrm{m} / \mathrm{s}) / \mathrm{m})$. The 1996 WIPP PA uses a model proposed in Ref. 29 to estimate the viscosity of drilling fluids. As discussed in Ref. 22, this model leads to the following expression for the Reynolds number associated with the helical flow of a drilling fluid within an annulus:

$$
R_{e}=0.8165 D_{e}\|\mathrm{~V}\| \rho_{f} / \eta_{\infty}
$$

where $D_{e},\|\mathbf{V}\|$ and $\rho_{f}$ are defined in conjunction with Eq. (8), and $\eta_{\infty}$ is the asymptotic value for the derivative of the shear stress $\left(\tau, \mathrm{kg} \mathrm{m}^{-1} \mathrm{~s}^{-2}\right)$ with respect to the shear rate $\left(\Gamma, \mathrm{s}^{-1}\right)$ obtained as the shear rate increases (i.e., $\eta_{\infty}=d \tau / d \Gamma$ as $\Gamma \rightarrow \infty$ ). The 1996 WIPP PA uses Eq. (9) to obtain the Reynolds numbers that are used to determine whether drilling fluids in the area of the drill collar are undergoing laminar or turbulent flow.

The Oldroyd model assumes that the shear stress $\tau$ is related to the shear rate $\Gamma$ by the relationship

$$
\tau=\eta_{0}\left(\frac{1+\sigma_{2} \Gamma^{2}}{1+\sigma_{1} \Gamma^{2}}\right) \Gamma
$$


where $\eta_{0}$ is the asymptotic value of the viscosity $\left(\mathrm{kg} \mathrm{m}^{-1} \mathrm{~s}^{-1}\right)$ that results as the shear rate $\Gamma$ approaches zero, and $\sigma_{1}, \sigma_{2}$ are constants $\left(\mathrm{s}^{2}\right)$. The expression leads to

$$
\eta_{\infty}=\eta_{0}\left(\sigma_{2} / \sigma_{1}\right)
$$

The 1996 WIPP PA uses values of $\eta_{0}=1.834 \times 10^{-2} \mathrm{~kg} \mathrm{~m}^{-1} \mathrm{~s}^{-1}, \sigma_{1}=1.082 \times 10^{-6} \mathrm{~s}^{2}$ and $\sigma_{2}=5.410 \times 10^{-7} \mathrm{~s}^{2}$ (Table 2-1, Sect. 7.0, Ref. 19; Ref. 27), and a resultant value of $\eta_{\infty}=9.17 \times 10^{-3} \mathrm{~kg} \mathrm{~m}^{-1} \mathrm{~s}^{-1}$. The quantity $\eta_{\infty}$ is comparable to the plastic viscosity of the fluid. ${ }^{22}$

As previously indicated, different models are used to determine the eroded diameter of a borehole (i.e., $2 R$ in Fig. 1, with $R=D_{f} / 2$ in Eq. (7)) depending on whether flow in the vicinity of the drill collar is laminar or turbulent. The model for borehole erosion in the presence of laminar flow is described next, and is then followed by a description of the model for borehole erosion in the presence of turbulent flow.

As shown in Ref. 30, the shear stresses associated with the laminar helical flow of a non-Newtonian fluid can be expressed as

$$
\tau(R, \rho)=\left\{\left[\frac{C}{\rho^{2}}\right]^{2}+\left[\frac{R J}{2}\left(\frac{\rho^{2}-\lambda^{2}}{\rho}\right)\right]^{2}\right\}^{1 / 2}
$$

for $R_{i} / R \leq \rho \leq 1$, where $R_{i}$ and $R$ are the inner and outer radii within which the flow occurs as indicated in Fig. $1 ; \tau(R$, $\rho)$ is the shear stress $\left(\mathrm{kg} \mathrm{m}^{-1} \mathrm{~s}^{-2}\right)$ at a radial distance $\Delta R$ beyond the inner boundary (i.e., at $\rho=\left(R_{i}+\Delta R\right) / R$ ); and the quantities $C, J$ and $\lambda$ are functions of $R$ that satisfy conditions indicated below. The shear stress at the outer boundary (i.e., $R$ ) is given by

$$
\tau(R, 1)=\left\{C^{2}+\left[\frac{R J}{2}\left(1-\lambda^{2}\right)\right]^{2}\right\}^{1 / 2} .
$$

As previously indicated, the borehole radius $R$ is assumed to increase as a result of erosional processes until a value of $R$ is reached at which $\tau(R, 1)$ is equal to the shear strength of the waste. In the 1996 WIPP PA, the shear strength of the waste is treated as an uncertain input variable (see WTAUFAIL in Table 1, Ref. 8). Computationally, determination of the eroded borehole diameter $R$ associated with a particular waste shear strength requires repeated evaluation of $\tau(R, 1)$, as indicated in Eq. (13), until a value of $R$ is determined for which $\tau(R, 1)$ equals that shear strength. 
The quantities $C, J$ and $\lambda$ must satisfy the following three conditions ${ }^{30}$ for the expression in Eq. (13) to be valid:

$$
\begin{aligned}
& 0=\int_{R_{i} / R}^{\lambda}\left(\frac{\rho^{2}-\lambda^{2}}{\rho \eta}\right) d \rho, \\
& 0=C \int_{R_{i} / R}^{l}\left(\frac{1}{\rho^{3} \eta}\right) d \rho-\Delta \Omega,
\end{aligned}
$$

and

$$
0=\frac{4 Q}{\pi R^{3}}+2 R J \int_{R_{i} / R}^{l}\left[\frac{\left(R_{i} / R\right)^{2}-\rho^{2}}{\eta}\right]\left[\frac{\rho^{2}-\lambda^{2}}{\rho}\right] d \rho,
$$

where $\eta$ is the drilling fluid viscosity $\left(\mathrm{kg} \mathrm{m}^{-1} \mathrm{~s}^{-1}\right)$ and is a function of $R$ and $\rho, \Delta \Omega$ is the drill string angular velocity $\left(\mathrm{rad} \mathrm{s}^{-1}\right)$, and $Q$ is the drilling fluid flow rate $\left(\mathrm{m}^{3} \mathrm{~s}^{-1}\right)$.

The viscosity $\eta$ in Eqs. (14) - (16) is introduced into the analysis through the assumption that the drilling fluid follows the Oldroyd model for shear stress in Eq. (10). In particular, because

$$
\tau=\eta \Gamma
$$

as a result of the definition of the viscosity $\eta$ and

$$
\Gamma^{2}=\left(\eta-\eta_{0}\right) /\left(\eta_{0} \sigma_{2}-\eta \sigma_{1}\right)
$$

from Eq. (10), the expression in Eq. (12) can be reformulated as

$$
\frac{\eta^{2}\left(\eta-\eta_{0}\right)}{\left(\eta_{0} \sigma_{2}-\eta \sigma_{1}\right)}=\left[\frac{C}{\rho^{2}}\right]^{2}+\left[\frac{R J}{2}\left(\frac{\rho^{2}-\lambda^{2}}{\rho}\right)\right]^{2}
$$

As discussed in Ref. 27 and also in Ref. 30, the expressions in Eqs. (14) - (16) and (4.5.14) can be numerically evaluated to obtain $C, J$ and $\lambda$ for use in Eqs. (12) and (13). In the 1996 WIPP PA, $\Delta \Omega=7.8 \mathrm{rad} \mathrm{s}^{-1}$ (Sect. 7.0, Ref. 19),

$$
Q=\|\mathbf{v}\|\left(\pi R^{2}-\pi R_{i}^{2}\right)
$$

where $\|\mathbf{V}\|=0.7089 \mathrm{~m} \mathrm{~s}^{-1}$ as used in Eq. (8), and $\eta_{0}, \sigma_{1}$ and $\sigma_{2}$ are defined in conjunction with Eq. (11). 
The model for borehole erosion in the presence of turbulent flow is now described. Unlike the theoretically derived relationship for erosion in the presence of laminar flow, the model for borehole erosion in the presence of turbulent flow is empirically based. In particular, pressure loss for axial flow in an annulus under turbulent flow conditions can be approximated in Ref. 22 .

$$
\Delta P=\frac{2 f L \rho_{f}\|\mathbf{v}\|^{2}}{0.8165 D_{e}}
$$

where $\Delta P$ is the pressure change $(\mathrm{Pa}), L$ is distance $(\mathrm{m})$ over which pressure change $\Delta P$ occurs, $f$ is the Fanning friction factor (dimensionless), and $\rho_{f},\|\mathbf{v}\|$ and $D_{e}$ are defined in conjunction with Eq. (8).

For pipe flow, $f$ is empirically related to the Reynolds number $R_{e}$ and a roughness term $\varepsilon$ in Ref. 31

$$
\frac{1}{f^{1 / 2}}=-4 \log _{10}\left(\frac{\varepsilon}{3.72 D}+\frac{1.255}{R_{e} f^{1 / 2}}\right)
$$

where $D$ is the inside diameter $(\mathrm{m})$ of the pipe and $\varepsilon$ is the average depth $(\mathrm{m})$ of pipe wall irregularities. In the absence of a similar equation for flow in an annulus, Eq. (22) is used in the 1996 WIPP PA to define $f$ for use in Eq. (21), with $D$ replaced by the effective diameter $D_{e}=2\left(R-R_{i}\right)$ and $\varepsilon$ equal to the average depth of irregularities in the waste-borehole interface. In the present analysis, $\varepsilon=0.025 \mathrm{~m}$ (Sect. 7.0, Ref. 19), which exceeds the value often chosen for use in calculations involving very rough concrete or riveted steel piping. ${ }^{32}$ Further, the Reynolds number $R_{e}$ is defined in Eq. (9).

The pressure change $\Delta P$ in Eq. (21) and the corresponding shear stress $\tau$ at the walls of the annulus are approximately related by

$$
\Delta P\left[\pi\left(R^{2}-R_{i}^{2}\right)\right]=\tau\left[2 \pi L\left(R+R_{i}\right)\right]
$$

where $\pi\left(R^{2}-R_{i}^{2}\right)$ is the cross-sectional area of the annulus (see Fig. 1) and $2 \pi L\left(R+R_{i}\right)$ is the total (i.e., interior and exterior) surface area of the annulus. Rearrangement of Eq. (23) and use of the relationship in Eq. (21) yields

$$
\tau=\frac{f \rho_{f}\|\mathbf{v}\|^{2}}{2(0.8165)}
$$

which was used in the 1991 and 1992 WIPP PAs (Refs. 25, 33) to define the shear stress at the surface of a borehole of radius $R$. As a reminder, $R$ enters into Eq. (14) through the use of $D=2\left(R-R_{i}\right)$ in the definition of $f$ in Eq. (22). As in the case for laminar flow, the borehole radius $R$ is assumed to increase until a value of $\tau$ (actually, $\tau(R)$ ) is reached that equals the shear strength of the waste (i.e., the uncertain analysis input WTAUFAIL in Table 1, Ref. 8). 
Computationally, the eroded borehole diameter is determined by solving Eq. (24) for $R$ under the assumption that $\tau$ equals the assumed shear strength of the waste.

In the 1996 WIPP PA, a slight modification to the definition of $\tau$ in Eq. (24) was made to account for drillstring rotation when fluid flow in the vicinity of the drill collars is turbulent. ${ }^{34,} 35$ Specifically, an axial flow velocity correction factor (i.e., a rotation factor), $F_{r}$, was introduced into the definition of $\tau$. The correction factor $F_{r}$ is defined by

$$
F_{r}=\left\|\mathbf{v}_{2100}\right\| /\|\mathbf{v}\|
$$

where $\left\|\mathbf{V}_{2100}\right\|$ is the norm of the flow velocity required for the eroded diameters to be the same for turbulent and laminar flow at a Reynolds number of 2100 and is obtained by solving

$$
\tau_{\text {fail }}=\frac{f \rho_{f}\left\|\mathbf{v}_{2100}\right\|^{2}}{2(0.8165)}
$$

for $\left\|\mathbf{v}_{2100}\right\|$ with $D$ in the definition of $f$ in Eq. (22) assigned the final diameter value that results for laminar flow at a Reynolds number of $R_{e}=2100$ (i.e., the $D$ in $D_{e}=2\left(R-R_{i}\right)=D-2 R_{i}$ obtained from Eq. (9) with $R_{e}=2100$ ). The modified definition of $\tau$ is

$$
\tau=\frac{f \rho_{f}\left(F_{r}\|\mathrm{v}\|\right)^{2}}{2(0.8165)}
$$

and results in turbulent and laminar flow having the same eroded diameter at a Reynolds number of 2100 , which is the Reynolds number at which a transition between turbulent and laminar flow is assumed to take place.

The following algorithm was used to determine the final eroded radius $R_{f}$ of a borehole and incorporates the possible occurrence of a transition from turbulent to laminar fluid flow within a borehole:

Step 1. Use Eq. (9) to determine an initial Reynolds number $R_{e}$, with $R$ set to the drill bit radius (i.e., $R_{0}$ ). In the 1996 WIPP PA, $R_{0}=12.25$ in (Sect. 7.0, Ref. 19).

Step 2. If $R_{e}<2100$, then the flow is laminar and the procedures discussed in conjunction with Eqs. (12) and (13) are used to determine $R_{f}$. Because any increase in the borehole diameter will cause the Reynolds number to decrease, the flow will remain laminar and there is no need to consider the possibility of turbulent flow as the borehole diameter increases, with the result that $R_{f}$ determined in this step is the final eroded radius of the borehole.

Step 3. If $R_{e} \geq 2100$, then the flow is turbulent and the procedures discussed in conjunction with Eqs. (24) and (27) are used to determine $R_{f}$. Once $R_{f}$ is determined, the associated Reynolds number $R_{e}$ is calculated with Eq. (9) 
and $R=R_{f}$. If $R_{e}>2100$, then a transition from turbulent to laminar flow cannot take place, and the final eroded radius is $R_{f}$ determined in this step.

Step 4. If the Reynolds number $R_{e}$ determined in Step 3 satisfies the inequality $R_{e} \leq 2100$, then a transition from turbulent to laminar flow is assumed to have taken place. In this case, the calculation of $R_{f}$ is redone for laminar flow, with the outer borehole radius $R$ initially defined to be the radius at which the transition from turbulent to laminar flow occurs (i.e., the radius associated with $R_{e}=2100$ ). In particular, the initial value for $R$ is given by

$$
R=R_{i}+\frac{2100 \eta_{\infty}}{2(0.8165)\|\mathbf{v}\| \rho}
$$

which is obtained from Eq. (9) by solving for $R$ with $R_{e}=2100$. A new value for $R_{f}$ is then calculated with the procedures discussed in conjunction with Eqs. (12) and (13) for laminar flow, with this value of $R_{f}$ replacing the value from step 3 as the final eroded diameter of the borehole.

Step 5. Once $R_{f}$ is known, the amount of waste removed to the surface is determined by Eq. (7) with $D_{f}=2 R_{f}$.

Additional information on CUTTINGS_S and its use in the 1996 WIPP PA to determine cuttings and cavings releases can be found in the CUTTINGS_S users manual ${ }^{36}$ and in the analysis package for cuttings and spallings releases. ${ }^{19}$

\section{Cuttings and Cavings: Uncertainty and Sensitivity Analysis}

Drilling intrusions through the waste panels can penetrate CH- or RH-TRU waste; specifically, the probabilities that a single intrusion through a waste panel will encounter $\mathrm{CH}$ - or RH-TRU waste are 0.880 and 0.120 , respectively (Sect. 7, Ref. 7). As the penetration of CH-TRU waste is more likely than the penetration of RH-TRU waste and the average concentrations of CH-TRU waste are similar to those for RH-TRU waste (Fig. 2), the cuttings and cavings release is dominated by CH-TRU waste.

The volume of material removed by a drilling intrusion through RH-TRU waste is fixed at $0.039 \mathrm{~m}^{3}$. Specifically, the drill bit diameter is fixed at $0.31115 \mathrm{~m}$, which yields an intersection area of $0.076 \mathrm{~m}^{2}$; the effective height of RH-TRU waste is assumed to be $0.509 \mathrm{~m}$; and no outward erosion of the borehole is assumed to take place (i.e., no cavings release takes place for a drilling intrusion through RH-TRU waste) (Sect. 2). However, uncertainty in inputs used in the 1996 WIPP PA results in the volume of material removed by cuttings and cavings due to a drilling intrusion through CH-TRU waste ranging from approximately $0.4 \mathrm{~m}^{3}$ to $3 \mathrm{~m}^{3}$ (Fig. 3), with the range of results in Fig. 3 resulting from the pooling of three individual Latin hypercube samples (LHSs) of size 100 each (i.e., replicates R1, R2, R3 in Eq. (7), Ref. 8). The uncertainty in the volume of CH-TRU waste removed as cuttings and 
cavings is determined by the variable WTAUFAIL (Fig. 4), which is the only variable in the LHS (see Table 1, Ref. 8) that is used in the calculation of the cuttings and cavings release.

The volumes in Fig. 3 and also the volume indicated above for RH-TRU waste are the original (i.e., uncompacted) volumes of the removed waste. The use of uncompacted volumes simplifies the calculation of the radionuclide concentrations used in the determination of cuttings releases and permits a combining of removal volumes for intrusions at different times.

\section{Cuttings and Cavings: CCDFs}

Complementary cumulative distribution functions (CCDFs) for cuttings and cavings are constructed conditionally on individual LHS elements $\mathbf{x}_{s u, k}, k=1,2, \ldots, n L H S$, by randomly sampling futures $\mathbf{x}_{s t}$ from the sample space $\mathrm{S}_{s t}$ associated with the probability space $\left(\mathrm{S}_{s t}, \& \quad s t, p_{s t}\right)$ for stochastic uncertainty (see Eq. (4)). Once the normalized releases are available, construction of the corresponding CCDF is straightforward (Sect. 11, Ref. 7).

The cuttings and cavings release for a given drilling intrusion is the product of the volume of waste removed $\left(\mathrm{m}^{3}\right)$ and the radionuclide concentration (EPA units $/ \mathrm{m}^{3}$ ) in the removed waste. For RH-TRU waste, the indicated concentration corresponds to the concentrations plotted in Fig. 2 (see $C_{R H}(k)$ in Table 1). For CH-TRU waste, the situation is more complex due to the presence of 569 waste streams (i.e., distinct types of waste), with each of the waste drums placed in the repository containing waste from only one waste stream (see $C_{C H}\left(j, \tau_{k}\right), P_{C H}(j)$ in Table 1). As a result, a single drilling intrusion through $\mathrm{CH}-\mathrm{TRU}$ waste can intersect several different waste streams. Given that waste drums containing CH-TRU waste are stacked three high in the repository, the concentration of $\mathrm{CH}$ TRU waste associated with a specific intrusion is taken to be the average of the concentrations associated with three randomly selected waste streams (Sect. 7, Ref. 7), which results in considerable variability in the size of the cuttings and cavings releases for individual intrusions (Fig. 5).

The resultant CCDF can be formally represented by

$$
\begin{aligned}
\operatorname{prob}_{C}(\operatorname{Rel}>R) & =\int_{S_{s t}} \delta_{R}\left[f_{C}\left(\mathbf{x}_{s t}, \mathbf{x}_{s u, k}\right)\right] d_{s t}\left(\mathbf{x}_{s t} \mid \mathbf{x}_{s u, k}\right) d V_{s t} \\
& \doteq \sum_{i=1}^{n S} \delta_{R}\left[f_{C}\left(\mathbf{x}_{s t, i}, \mathbf{x}_{s u, k}\right)\right] / n S
\end{aligned}
$$

where the dependence on the elements of the LHS has been added to the expressions in Eqs. (2) and (4). In the preceding approximation, a cuttings and cavings release $f_{C}\left(\mathbf{x}_{s t, i}, \mathbf{x}_{s u, k}\right)$ must be estimated for each sampled future $\mathbf{x}_{s t, i^{*}}$ 
As a reminder, each future $\mathbf{x}_{s t}$ has the form

$$
\mathbf{x}_{s t}=[\underbrace{t_{1}, l_{1}, e_{1}, b_{1}, p_{1}, \mathbf{a}_{1}}_{1^{\text {st }} \text { intrusion }}, \underbrace{t_{2}, l_{2}, e_{2}, b_{2}, p_{2}, \mathbf{a}_{2}}_{2^{\text {nd }} \text { intrusion }}, \ldots, \underbrace{t_{n}, l_{n}, e_{n}, b_{n}, p_{n}, \mathbf{a}_{n}}_{n^{\text {th }} \text { intrusion }}, t_{\min }],
$$

where $n$ is the number of drilling intrusions in the vicinity of the repository, $t_{i}$ is the time (yr) of the $i^{\text {th }}$ intrusion, $l_{i}$ designates the location of the $i^{\text {th }}$ intrusion, $e_{i}$ designates the penetration of an excavated or nonexcavated area by the $i^{\text {th }}$ intrusion, $b_{i}$ designates where or not the $i^{\text {th }}$ intrusion penetrates pressurized brine in the Castile Formation, $p_{i}$ designates the plugging procedure used with the $i^{\text {th }}$ intrusion (i.e., continuous plug, two discrete plugs, three discrete plugs), $\mathbf{a}_{i}$ designates the type of waste penetrated by the $i^{\text {th }}$ intrusion (i.e., no waste, contact-handled $(\mathrm{CH})$ waste, remotely-handled $(\mathrm{RH})$ waste), and $t_{\min }$ is the time at which potash mining occurs within the land withdrawal boundary (Sect. 3, Ref. 6; Ref. 7).

In turn, the cuttings and cavings release to the accessible environment for a given future $\mathbf{x}_{s t}$ is given by

$$
f_{C}\left(\mathbf{x}_{s t}\right)=\sum_{i=1}^{n} r C_{i}
$$

where

$$
\begin{aligned}
r C_{i} & =0 & & \text { if } \mathbf{a}_{i} \sim \text { no waste } \\
& =A_{C H} H_{C H} F_{C H}\left\{\sum_{r=1}^{3} C_{C H}\left[j(i, r), t_{i}\right] / 3\right\} & & \text { if } \mathbf{a}_{i} \sim \text { CH-TRU waste } \\
& =A_{R H} H_{R H} F_{R H} C_{R H}\left(t_{i}\right) & & \text { if } \mathbf{a}_{i} \sim \text { RH-TRU waste }
\end{aligned}
$$

$j(i, r)=$ an integer randomly selected from $1,2, \ldots, 569$ for $r=1,2,3$ in consistency with the probabilities $P_{C H}(j), j=1,2, \ldots, 569$,

and all remaining symbols are defined in Table 1. The summation from $r=1$ to $r=3$ corresponds to the determination of an average concentration over three randomly selected waste streams. Further, the appearance of $t_{i}$ in $C_{C H}\left[j(i, r), t_{i}\right]$ and $C_{R H}\left(t_{i}\right)$ implies linear interpolation between the actual time values in Table 1 at which $C_{C H}$ and $C_{R H}$ are available.

For each LHS element, $n S=10,000$ futures are randomly selected (Sect. 10, Ref. 7) and the corresponding cuttings and cavings releases are determined as shown in Eq. (31). The resultant CCDFs (Sect. 11, Ref. 7) for cuttings and cavings releases to the accessible environment are then constructed (Fig. 6). In Fig. 6 and other similar figures in this presentation, the left frame shows the distribution of CCDFs obtained with the first of the three replicated LHSs (i.e., replicate R1; see Sect. 8, Ref. 8), and the right frame shows the mean and percentile curves that result from pooling all three replicates (i.e., replicates $R 1, R 2$ and $R 3$ ) to obtain a sample of size 300 . All the 
CCDFs fall below the boundary line specified in 191.13(a) (Sect. 2, Ref. 6). Further, the distribution of CCDFs is relatively tight, and the estimates for the mean and percentile curves are quite stable (Fig. 7; see Sect. 7, Ref. 8). Indeed, the three estimates for the mean and percentile curves are essentially indistinguishable at the plotting resolution of Fig. 7 .

In Fig. 6 and other similar figures in this presentation, CCDFs end at the largest observed consequence value. From there, they drop vertically to zero; this drop is not shown to avoid a solid mass of vertical lines beneath the lowest observed exceedance probabilities (see Sect. 11, Fig. 14, Ref. 7). Once a CCDF reaches zero on the probability axis (i.e., the ordinate), it continues right along the consequence axis (i.e., the abscissa). As a result, the mean CCDF has nonzero exceedance probabilities that fall below the nonzero exceedance probabilities of the individual CCDFs that were averaged in its construction. Similar plotting conventions hold for the quantile curves.

As volume of removed waste (i.e., $A_{C H} H_{C H}$ as used in conjunction with Eq. (31)) is the only quantity used in the determination of cuttings and cavings releases that is affected by variables in the LHS, the uncertainty in the CCDFs shown in Fig. 6 is due entirely to WTAUFAIL (Fig. 4). This assertion can be checked by reducing each CCDF for cuttings and cavings removal to an expected value and then regressing this expected value on the sampled variables. The outcome of this calculation is the rank-regression ${ }^{40}$ model

$$
\bar{y}_{C}=300.8-0.9989 \text { WTAUFAIL }
$$

with an $R^{2}$ value of 0.9979 , where $\bar{y}_{C}$ designates the expected value associated with a CCDF for cuttings and cavings removal and the indicated regression model was obtained with the STEPWISE program. ${ }^{41,42}$ Thus, WTAUFAIL is indeed the only variable that affects the CCDFs for cuttings and cavings removal. The corresponding scatterplot appears in Fig. 8.

The CCDFs in Fig. 6 are for normalized release, which is not a very intuitive quantity. To help provide perspective, CCDFs for volume of material brought to the surface (i.e., the quantity obtained from Eq. (31) when $F_{C H}, C_{C H}, F_{R H}$ and $C_{R H}$ are equal to 1 ) can also be constructed (Fig. 9). The release of more than $10 \mathrm{~m}^{3}$ of material over 10,000 yr is unlikely.

\section{Spallings: Volume Removed}

The spallings model used in the 1996 WIPP PA estimates the release of solid material carried to a borehole by venting gas after a drilling intrusion. Such releases are assumed to have the potential to occur when the pressure in the repository at the time of a drilling intrusion exceeds $8 \mathrm{MPa}$, which is the pressure exerted by a column of brinesaturated drilling fluid at the depth of the repository. ${ }^{43}$ If repository pressure is less than $8 \mathrm{MPa}$, then no gas venting into the borehole, and hence no spallings release, is assumed. 
Results from steady state flow experiments through granular thaterial in a cylindrical geometry indicate that a pattern of channels would be formed in the waste by venting gas in the vicinity of an intruding borehole. ${ }^{44}$ Based on these results, the following conceptual model for spallings releases at pressures above $8 \mathrm{MPa}$ was formulated: (1) Immediately after a drilling intrusion, pressure gradients associated with the flow of gas towards the borehole fracture the porous waste material, thus permitting the escaping gas to flow within the fractures rather than through the porous waste. Consequently, the waste permeability does not affect gas flow, and the gas pressure at the borehole entrance can be assumed to be the initial (i.e., the time of the intrusion) gas pressure in the repository. (2) The gas flow velocity up the borehole is determined by the properties of isothermal gas flow in a long tube of a given cross-sectional area, tube roughness, and gas pressure at the borehole entrance. (3) The total mass flow rate of gas in the fractures at any radial distance from the borehole is equal to the mass flow rate of gas up the borehole. (4) Erosion of solid material occurs within the fractures when the gas velocity exceeds a fracture erosion velocity $v_{e}$. (5) The fracture erosion velocity $v_{e}$ is related to drag forces on a particle and the cohesive strength that results from moisture and cementation in the matrix. (6) The development of the fracture system is not limited by the amount of gas available for venting.

The mathematical implementation of the preceding conceptual model is now described. With the assumption that gas pressure, and hence gas density, is approximately constant throughout the waste, conservation of mass requires that

$$
2 \pi r v_{a}(r) H=A_{B H} v_{B H}
$$

or, equivalently, that

$$
v_{a}(r)=A_{B H} v_{B H} /(2 \pi r H)
$$

where $v_{a}(r)$ is the average gas velocity $(\mathrm{m} / \mathrm{s})$ in the waste at a distance $r(\mathrm{~m})$ from the borehole, $H$ is the height $(\mathrm{m})$ of a repository room at the time of the intrusion, $A_{B H}$ is the area $\left(\mathrm{m}^{2}\right)$ of the annulus between the drill pipe and the borehole wall (Fig. 1), and $v_{B H}$ is the gas velocity (m/s) up the borehole. The determination of $v_{B H}$ is discussed later. As the gas flow is assumed to take place predominately within the induced fracture system, the gas velocity $v_{f}(r)$ $(\mathrm{m} / \mathrm{s})$ within the fractures is given by

$$
v_{f}(r)=v_{a}(r) / \phi_{f}(r)
$$

where $\phi_{f}(r)$ is the fracture porosity at a distance $r$ from the borehole.

The fractures are assumed to grow in size until the gas velocity within them is reduced to the minimum velocity $v_{e}(\mathrm{~m} / \mathrm{s})$ required to cause erosion of the fracture surfaces. When $v_{\mathcal{e}}$ is reached at a given distance $r$ from the 
borehole, erosion of material from the fractures will cease. Thus, the final (i.e., maximum) fracture porosity $\phi_{f e}(r)$ at a distance $r$ from the borehole is given by

$$
\phi_{f e}(r)=v_{a}(r) / v_{e}=\left(A_{B H} v_{B H}\right) /\left(2 \pi r H v_{e}\right)
$$

The velocity $v_{e}$ is a property of the waste and its derivation will be discussed later. Given that $v_{e}$ is known, the solid volume $V_{\text {sol }}\left(\mathrm{m}^{3}\right)$ eroded (i.e., spalled) from the fractures is

$$
V_{\text {sol }}=\int_{0}^{2 \pi} \int_{0}^{r_{0}} H(1-\phi) \phi_{f e}(r) r d r d \theta=A_{B H^{v}} v_{B H} r_{0}(1-\phi) / v_{e}
$$

where $\phi$ is the bulk porosity of the waste at the time of the intrusion and $r_{0}$ is the equivalent radius (m) of a waste disposal room. The presence of 1- $\phi$ in Eq. (37) results in the spallings volume $V_{\text {sol }}$ being taken only from the solid components of the waste. The porosity $\phi$ is obtained from solution of Eqs. (2) - (7) of Ref. 9 by BRAGFLO and is a function of intrusion time. Further, in the 1996 WIPP PA, $A_{B H}=4.36 \times 10^{-2} \mathrm{~m}^{2}$ (i.e., $\pi\left(r_{b}-r_{c}\right)^{2}$, where $r_{b}=$ $(0.311 \mathrm{~m}) / 2$ is the drill bit radius and $r_{p}=(0.2032 \mathrm{~m}) / 2$ is the drill pipe radius) and $r_{0}=17.1 \mathrm{~m}$ (Sect. 7.0, Ref. 19).

The volume $V_{\text {sol }}$ in Eq. (37) is the volume of solid material removed by spallings. The equivalent volume of original uncompacted material can be obtained from the equality

$$
\phi_{i}=\left(V_{i}-V_{s o l}\right) / V_{i}
$$

where $\phi_{i}$ is the original (i.e., uncompacted) porosity of the waste and $V_{i}$ is the original volume $\left(\mathrm{m}^{3}\right)$ of material that gave rise to a spallings release of size $V_{\text {sol. }}$. In turn,

$$
V_{i}=V_{\text {sol }} /\left(1-\phi_{i}\right)=\left(A_{B H} v_{B H} r_{0} / v_{e}\right)(1-\phi) /\left(1-\phi_{i}\right)
$$

In the 1996 WIPP PA, radionuclide concentrations were calculated for original uncompacted waste, and so $V_{i}$ rather than $V_{\text {sol }}$ was used in the determination of the normalized releases due to spallings.

Two important quantities, $v_{e}$ and $v_{B H}$, used in the calculation of $V_{i}$ and $V_{\text {sol }}$ remain to be discussed. The determination of $v_{e}$ is described first (Sect. 7) and then followed by a description of the determination of $v_{B H}$ (Sect. 8).

\section{Spallings: Fracture Erosion Velocity}

The fracture erosion velocity $v_{e}$ is the gas velocity in a fracture required to erode the fracture walls. One possibility is to define $v_{e}$ to be the terminal velocity of a falling spherical particle as this is the velocity at which the 
weight of the particle equals the drag forces on the particle. As discussed in Ref. 45 (p. 30), this results in the relationship

$$
v_{e}^{2}=\frac{4 g d\left(\rho_{s}-\rho_{g}\right)}{3 C_{D}\left[R_{e}\left(v_{e}\right)\right] \rho_{g}},
$$

where $g$ is the acceleration due to gravity $\left(\mathrm{m} / \mathrm{s}^{2}\right), d$ is the particle diameter $(\mathrm{m}), \rho_{s}$ is the particle density $\left(\mathrm{kg} / \mathrm{m}^{3}\right), \rho_{g}$ is the gas density $\left(\mathrm{kg} / \mathrm{m}^{3}\right)$, and $C_{D}\left[R_{e}\left(v_{e}\right)\right]$ is the coefficient of drag and a function of the Reynolds number $R_{e}\left(v_{e}\right)$. In turn, $R_{e}\left(v_{e}\right)$ and $C_{D}\left[R_{e}\left(v_{e}\right)\right]$ are defined empirically (p. 406, Ref. 46) by

$$
\begin{array}{rlrl}
R_{e}\left(v_{e}\right)=\rho_{g} v_{e} d / \mu & \\
\log _{10}\left\{C_{D}\left[R_{e}\left(v_{e}\right)\right]\right\} & =\log _{10}\left[24 / R_{e}\left(v_{e}\right)\right] & & \text { if } R_{e}\left(v_{e}\right)<0.4 \\
& =\sum_{i=0}^{6} a_{i}\left[\log _{10} R_{e}\left(v_{e}\right)\right]^{i} & & \text { if } 0.4 \leq R_{e}\left(v_{e}\right) \leq 2 \times 10^{5} \\
& =\log _{10}(0.2), & & \text { if } R_{e}\left(v_{e}\right) \geq 2 \times 10^{5}
\end{array}
$$

where $\mu$ is the gas viscosity ( $\mathrm{Pa} \bullet \mathrm{s}$ ) and the $a_{i}$ in Eq. (43) are empirically determined from the relationship given by Ref. 46, using the program GRAPHER, Version 1.23, from Golden Software Inc., Golden CO, to be (Sect. 7.0, Ref. 19)

$$
\begin{aligned}
& a_{0}=1.3918, a_{1}=-0.907723, a_{2}=0.136371, a_{3}=0.0165093 \\
& a_{4}=-0.0285484, a_{5}=0.00933281, a_{6}=-0.000897166 .
\end{aligned}
$$

The velocity $v_{e}$ can then be determined by numerical solution of Eq. (40) subject to the constraints in Eqs. (41) (44).

The use of Eq. (40) to determine $v_{e}$ results in drag being the only resistance to particle movement. In reality, the tensile strength of the waste also resists erosion in fractures by flowing gas and should be incorporated into the derivation of $v_{e}$. As now described, one way to do this is by replacing the gravity term $g$ in Eq. (40) by an effective gravity force $g_{\text {eff }}$ that derives from both drag and the tensile strength of the waste.

The parting force $p_{f}\left(\mathrm{~kg} \mathrm{~m} / \mathrm{s}^{2}\right)$ on a particle can be expressed as

$$
\sigma=\frac{p_{f}}{p_{a}}=\frac{m g_{t}}{\pi R^{2}}=\frac{4 \pi R^{3} \rho_{s} g_{t} / 3}{\pi R^{2}}=4 \rho_{s} g_{t} R / 3
$$


where $\sigma$ is the tensile strength $\left(\mathrm{kg} / \mathrm{ms}^{2}\right), p_{a}$ is the effective particle area (i.e., $\left.\pi R^{2}\right)(\mathrm{m}), m$ is the particle mass $(\mathrm{kg}), R$ is the particle radius $(\mathrm{m}), \rho_{s}$ is the particle density $\left(\mathrm{kg} / \mathrm{m}^{3}\right)$, and $g_{t}$ is the force $\left(\mathrm{kg} / \mathrm{ms}^{2}\right)$ (i.e., the effective acceleration due to gravity) necessary to generate a particle weight equal to the parting force $p_{f}$. Solution of Eq. (45) for $g_{t}$ then yields

$$
g_{t}=3 \sigma /\left(4 \rho_{s} R\right)
$$

An effective acceleration due to gravity $g_{e f f}\left(\mathrm{~m} / \mathrm{s}^{2}\right)$ that accounts for both drag and tensile strength can now be defined by

$$
\begin{aligned}
g_{\text {eff }} & =g+g_{t} \\
& =g+3 \sigma /\left(4 \rho_{s} R\right) \\
& =g+3 \sigma_{p} /\left(4 \rho_{s} R\right)+3 \sigma_{c} /\left(4 \rho_{s} R\right),
\end{aligned}
$$

with the last equality following from the assumption that $\sigma=\sigma_{p}+\sigma_{c}$ has a component $\sigma_{p}$ resulting from pore water and a component $\sigma_{c}$ resulting from intergranular cementation.

The value for $g_{\text {eff }}$ in Eq. (47) was obtained for an unconstrained system. For the determination of spallings releases, $g_{\text {eff }}$ will be used for flow in channels. In this situation, it is desirable to add effectiveness factors ${ }^{44}$ to account for the constrained conditions associated with flow in small channels. When this is done, $g_{\text {eff }}$ becomes

$$
g_{e f f}=F_{g e} g+3 F_{p e} \sigma_{p} /\left(4 \rho_{s} R\right)+3 F_{c e} \sigma_{c} /\left(4 \rho_{s} R\right)
$$

where $F_{g e}, F_{p e}$ and $F_{c e}$ are empirically determined effectiveness factors for drag forces, shear strength associated pore water, and shear strength associated with intergranular cementation, respectively. ${ }_{4} 4$

In the 1996 WIPP PA, $g_{\text {eff }}$ as defined in Eq. (48) was used instead of $g$ in Eq. (40) in the numerical determination of $v_{e}$. In this determination, the following additional values were also used (Sect. 7.0, Ref. 19): $\rho_{s}=$ $2650 \mathrm{~kg} / \mathrm{m}^{3}, \rho_{g}=0.0726 \mathrm{~kg} / \mathrm{m}^{3}, \mu=9.2 \times 10^{-6} \mathrm{~Pa} \bullet \mathrm{s}, \sigma_{p}=0 \mathrm{~kg} / \mathrm{ms}^{2}, \sigma_{c}=6895 \mathrm{~kg} / \mathrm{ms}^{2}, F_{g e}=18.1, F_{p e}=0, F_{c e}=$ $1.0, R=d / 2$, and the particle diameter $d$ was an uncertain analysis input (see WPRTDIAM in Table 1, Ref. 8).

\section{Gas Velocity in Borehole}

The borehole gas velocity $v_{B H}$ is given by

$$
v_{B H}=C M_{i},
$$


where $C=(K R T)^{1 / 2}$ is the local sound speed $(\mathrm{m} / \mathrm{s}), T$ is the absolute temperature $\left({ }^{\circ} \mathrm{K}\right), R=4123 \mathrm{~J} /(\mathrm{kg} \mathrm{s})$ is the universal gas constant for hydrogen (p. 541, Ref. 47), $K$ is the ratio of specific heat of hydrogen at constant pressure to specific heat of hydrogen at constant volume, and $M_{i}$ is the inlet Mach number. ${ }^{48}$

In turn, the inlet Mach number is computed based on flow in the borehole annulus with the assumption that the borehole is free of drilling fluid. Compressible, isothermal flow of a gas in a channel (i.e., the borehole annulus) is characterized by the following equation: ${ }^{48}$

$$
f L / D=\left(1-P_{o}^{2} / P_{i}^{2}\right)\left(K M_{i}^{2}\right)^{-1}-2 \ln \left(P_{i} / P_{o}\right)
$$

where $f$ is the friction factor (dimensionless), $D$ is the channel diameter $(\mathrm{m}), L$ is the channel length (m), and $P_{i}$ and $P_{o}$ are the inlet and outlet gas pressures $(\mathrm{Pa})$. In this analysis, $D$ is the effective diameter for the borehole annulus (i.e., the diameter of a circle that has the same area as the borehole annulus).

Due to the difference in $D$ depending on whether flow is in the area of the drill collar or the drill pipe (Fig. 1), Eq. (50) must be applied over two intervals (i.e., the drill collar and the much longer drill pipe) in the estimation of $M_{i}$ for use in the determination of $v_{B H}$. This division produces the following two equations:

$$
\begin{aligned}
& f L_{c} / D_{c}=\left(1-P_{c-p}^{2} / P_{i}^{2}\right)\left(K M_{i}^{2}\right)^{-1}-2 \ln \left(P_{i} / P_{c-p}\right) \\
& f L_{p} / D_{p}=\left(1-P_{o}^{2} / P_{c-p}^{2}\right)\left[K M_{i}^{2}\left(P_{i} / P_{c-p}\right)^{2}\left(D_{c} / D_{p}\right)^{4}\right]^{-1}-2 \ln \left(P_{c-p} / P_{o}\right),
\end{aligned}
$$

where $L_{c}$ and $L_{p}$ are the lengths (m) of the drill collar and the drill pipe, $D_{c}$ and $D_{p}$ are the effective diameters (m) for the annuli associated with the drill collar and the drill pipe, and $P_{c-p}$ is the gas pressure $(\mathrm{Pa})$ at the interface between the drill collar and the drill pipe.

The two preceding equations were numerically solved to obtain $M_{i}$ and $P_{c-p}$. In this solution, $f=0.08, L_{c}=$ $182.88 \mathrm{~m}, L_{p}=472.12 \mathrm{~m}, D_{c}=0.2032 \mathrm{~m}, D_{p}=0.1143 \mathrm{~m}, K=1.41, P_{i}=$ pressure $(\mathrm{Pa})$ in waste at time of drilling intrusion (obtained from numerical solution of Eqs. (2) - (7) of Ref. 9 by BRAGFLO) and $P_{o}$ equals atmospheric pressure (i.e., $89465 \mathrm{~Pa}$ ) or, if applicable, the pressure that corresponds to the condition that the rate of change of pressure with respect to length is unbounded (i.e., $d p / d l \rightarrow \infty$ at the pipe exit) (Sect. 7.0, Ref. 19). Once obtained, $M_{i}$ is then used in Eq. (49) to determine $v_{B H}$.

Additional information on CUTTINGS_S and its use in the 1996 WIPP PA to determine spallings releases can be found in the CUTTINGS_S users manual ${ }^{36}$ and in the analysis package for cuttings and spallings releases. ${ }^{19}$

\section{Spallings: Uncertainty and Sensitivity Analysis}


The spallings model predicts a release of solid material. For computational convenience and also for comparability with cuttings results, the released volume of material is reported as volume of original, uncompacted material emplaced in the repository. For a given drilling intrusion, this volume is multiplied by the average concentration (EPA units $/ \mathrm{m}^{3}$ ) of CH-TRU waste in the waste panels (Fig. 2) at the time of the intrusion to produce the spallings release. Due to the low permeability of the region surrounding each RH-TRU waste canister, intrusions into RH-TRU waste are assumed not to produce spallings releases.

The size of the spallings release is sensitive to the pressure in the repository at the time of the associated drilling intrusion. In turn, pressure is dependent on both the time of a drilling intrusion and whether or not that drilling intrusion has been preceded by earlier intrusions. Due to the $1^{\circ}$ dip of the repository, it is also possible that conditions influencing spallings may differ between upper panels (i.e., panels 1, 2, 3, 6, 7, 8, 9 in Fig. 1, Ref. 7) and lower panels (i.e., panels 4, 5, 10 in Fig. 1, Ref. 7).

For initial intrusions into the repository, spallings calculations were performed for intrusions at 100, 350, 1000, 3000, 5000 and 10,000 yr and also for intrusions into upper (U) and lower (L) waste panels (Fig. 10; Sect. 13, Ref. 7). Early intrusions often produced no releases, with the number of nonzero releases increasing with time due to increasing pressure in the repository (Fig. 10; also see Fig. 18, Ref. 16). The spallings model incorporates the assumption that no spallings release will take place when the repository pressure is less than $8 \mathrm{MPa}$, which results in the switch from zero to nonzero spallings releases illustrated in Fig. 11. This switch results because a column of saltsaturated drilling fluid that extends from the land surface to the repository would exert a pressure of approximately $8 \mathrm{MPa} ; 43$ thus, $8 \mathrm{MPa}$ is the minimum pressure that must be exceeded before repository fluids will displace the drilling fluid. The volume of the spallings release is between approximately 0.5 and $4 \mathrm{~m}^{3}$ and the corresponding normalized release is between approximately $3 \times 10^{-3}$ and $2 \times 10^{-2}$ EPA release units. The releases from intrusions into an upper or lower panel at the same time are essentially identical (Fig. 10), with this equality resulting because pressure was essentially equal throughout the repository (Fig. 8.3.2, Ref. 17) and the effects of brine saturation were not incorporated into the spallings model.

Although pressure determines whether or not a nonzero spallings release takes place, it has little effect on the actual size of the release (Fig. 11). Rather, given that a nonzero release takes place, the variable WPRTDIAM determines the actual size of this release (Fig. 12). Specifically, the size of the release increases as WPRTDIAM decreases.

At a value of WPRTDIAM $2.5 \times 10^{-3} \mathrm{~m}^{3}$ there is a noticeable change in behavior, with the volume of released material suddenly changing from approximately $2.5 \mathrm{~m}^{3}$ to a range of values bounded below by approximately $3.2 \mathrm{~m}^{3}$ (Fig. 12). This discontinuity is due to an abrupt change in the coefficient of drag for particles at a Reynolds number $(R e)$ of $2 \times 10^{5}$. Above $R e=2 \times 10^{5}$, the boundary layer on the forward surface of smooth spheres changes from laminar to turbulent flow and tends to move the boundary layer point of separation 
downstream. This causes the size of the wake to decrease and reduces pressure drag, which results in the observed discontinuity and larger releases for small values of WPRTDIAM (Ref. 46, pp. 404-408).

The patterns involving spallings release, pressure and WPRTDIAM are clearly revealed in a three-dimensional scatterplot, with no release taking place for pressures below $8 \mathrm{MPa}$ and the size of the release depending on WPRTDIAM for pressures above $8 \mathrm{MPa}$ (Fig. 13).

Spallings calculations were also performed for intrusions subsequent to an initial intrusion into the repository for the following cases (Sect. 12, Ref. 7): (1) An initial E1 intrusion at $350 \mathrm{yr}$ followed by a second intrusion at 550 , $750,2000,4000$ or 10,000 yr (Fig. 14), (2) An initial E1 intrusion at $1000 \mathrm{yr}$ followed by a second intrusion at 1200, $1400,3000,5000$ or 10,000 yr (Fig. 14), (3) An initial E2 intrusion at $350 \mathrm{yr}$ followed by a second intrusion at 550 , $750,2000,4000$ or $10,000 \mathrm{yr}$ (Fig. 15), and (4) An initial E2 intrusion at $1000 \mathrm{yr}$ followed by a second intrusion at $1200,1400,3000,5000$ or 10,000 yr (Fig. 15). Further, spallings releases were calculated for two cases for each of the second intrusion times: (1) Intrusion into the same waste panel as the first intrusion, and (2) Intrusion into a different waste panel than the first intrusion. Intrusion times 200 and 400 yrs after the initial intrusion time (i.e., 550 and $750 \mathrm{yr}$ for an initial intrusion at $350 \mathrm{yr}$, and 1200 and $1400 \mathrm{yr}$ for an initial intrusion at $1000 \mathrm{yr}$ ) were selected to give results just before and after the borehole plug at the Rustler/Salado interface is assumed to fail for plugging patterns 2 and 3 (Sect. 6; Ref. 7; Table 8, Ref. 9). Wider time intervals were used at later times because gas pressure tends to change rather slowly at later times (Fig. 18, Ref. 16; Fig. 28, Ref. 17), thus allowing larger times between calculations. The distinction between intrusion into same and different panels was made because of the possible effects of the resistance to flow between waste panels due to the presence of panel closures and the occurrence of brine flow down a borehole into the intruded panel.

Scatterplots for second intrusions equivalent to those in Figs. 12 and 13 for initial intrusions show exactly the same patterns, with the occurrence of a spallings release depending on whether or not the pressure is above $8 \mathrm{MPa}$ and the actual size of the release depending on WPRTDIAM. For most sample elements, there is no spallings release for the second intrusion because the pressure is less than $8 \mathrm{MPa}$ (Fig. 28, Ref. 17). As discussed in Sect. 4 of Ref. 17, this reduced pressure is due primarily to borehole permeability (i.e., $k=10^{x}, x=B H P R M$; see Table 1 , Ref. 8). The greatest number of nonzero spallings releases occurs when the second intrusion is $200 \mathrm{yr}$ after the first intrusion because the borehole plug at the Rustlet/Salado interface is yet to fail (Table 8, Ref. 9) and, as a result, the pressure has not been reduced by gas flow up the first borehole.

\section{Spallings: CCDFs}

As for cuttings and cavings (Sect. 5), each LHS element leads to a CCDF for spallings releases that is obtained by randomly sampling futures of the form in Eq. (30) and then constructing the corresponding spallings release for each future. The resultant CCDF can be formally represented by 


$$
\begin{aligned}
\operatorname{prob}_{S P}(R e l>R) & =\int_{S_{s t}} \delta_{R}\left\{f_{S P}\left[\mathbf{x}_{s t}, \mathbf{x}_{s u, k}, f_{B}\left(\mathbf{x}_{s t}, \mathbf{x}_{s u, k}\right)\right]\right\} d_{s t}\left(\mathbf{x}_{s t} \mid \mathbf{x}_{s u, k}\right) d V_{s t} \\
& \doteq \sum_{i=1}^{n S} \delta_{R}\left\{f_{S P}\left[\mathbf{x}_{s t, i}, \mathbf{x}_{s u, k}, f_{B}\left(\mathbf{x}_{s t, i}, \mathbf{x}_{s u, k}\right)\right]\right\} / n S
\end{aligned}
$$

where the dependence on elements of the LHS has been added to the expressions in Eqs. (3) and (5). In the preceding approximation, a spallings release must be constructed for each sample future $\mathbf{x}_{s t, i}$.

The construction of the spallings release is based on the volumes of material $\left(\mathrm{m}^{3}\right)$ released by spallings under different conditions and the radionuclide concentration (EPA units $/ \mathrm{m}^{3}$ ) in that material (Table 2). For each sampled intrusion time (see definition $\mathbf{x}_{s t}$ in Eq. (30)), radionuclide concentration can be obtained by interpolating on $C_{C H}\left(\tau_{k}\right)$. Further, for an initial intrusion, the volume of released material can be obtained by interpolating on $V S_{E 0, U}\left(\tau_{k}\right)$ and $V S_{E 0, L}\left(\tau_{k}\right)$. Obtaining results for second and subsequent intrusions is more difficult for two reasons. First, results are available for initial intrusions at only 350 and $1000 \mathrm{yr}$. Second, results are available for second intrusions but not for subsequent intrusions.

The availability of results for initial intrusions at only 350 and $1000 \mathrm{yr}$ is handled by extending these results to initial intrusions at other times on the basis of the assumption that elapsed time from the first to the second intrusion (i.e., $\Delta \tau_{j k}$ ) is the primary determinant of the spallings release for the second intrusion. Specifically, the following assignments are made:

$$
V S_{E 1, S}\left(\tau, \Delta \tau_{1 k}\right)=V S_{E 1, S}\left(\tau_{1}, \Delta \tau_{1 k}\right)
$$

for $100 \leq \tau \leq \tau_{1}=350 \mathrm{yr}$, and

$$
V S_{E 1, S}\left(\tau, \Delta \tau_{2 k}\right)=V S_{E 1, S}\left(\tau_{2}, \Delta \tau_{2 k}\right)
$$

for $\tau_{2}=1000 \leq \tau \leq 10,000 \mathrm{yr}$. Similar assignments are also made for $V S_{E 1, D}, V S_{E 2, S}$ and $V S_{E 2, D}$. The lack of results for more than two intrusions is handled by assuming that spallings releases for third and subsequent intrusions can be estimated by ignoring intermediate intrusions and treating the initial intrusion and the particular subsequent intrusion under consideration as if they were the only two intrusions in existence (Table 2).

For each LHS element, $n S=10,000$ futures are randomly selected and the corresponding spallings releases are determined as shown in Table 3. As an aside, the same 10,000 futures are used for all CCDF constructions for a given LHS element, which ultimately permits the combining of all release modes (i.e., cuttings and cavings, spallings, direct brine release, groundwater transport) into a single CCDF. The resultant CCDFs for spallings releases to the accessible environment are then constructed (Fig. 16). All the CCDFs fall below the boundary line specified in 191.13(a). Overall, the CCDFs tend to be farther from the boundary line and also more scattered than 
the CCDFs for cuttings and cavings (Fig. 6), with 18 out of $100 \mathrm{CCDFs}$ being degenerate (i.e., having no nonzero releases) for the first replicate. However, the distribution is still quite stable across the three replicates (Fig. 17).

The division of the CCDFs in Fig. 16 into four distinct groups depends on when an initial intrusion into the repository will produce nonzero releases. With the drilling rate into the excavated regions of the repository given by $\lambda=6.14 \times 10^{-6} \mathrm{yr}^{-1}$ during the $600 \mathrm{yr}$ of passive institutional controls (i.e., $\left(2.94 \times 10^{-5} \mathrm{yr}^{-1}\right)(0.209)$; see Sects. 2 , 4, Ref. 7) and by $\lambda=6.14 \times 10^{-4} \mathrm{yr}^{-1}$ after passive institutional controls are assumed to have ended (i.e., $\left(2.94 \times 10^{-3} \mathrm{yr}^{-1}\right)(0.209)$; see Sects. 2,3 , Ref. 7), the probabilities of no drilling intrusions by 1000,3000 and 5000 yrs are given by $0.83,0.24$ and 0.071 , respectively. These probabilities approximately correspond to where the three lower groups of CCDFs emerge from the ordinate, with these groups resulting from sample elements in which repository pressure has not reached $8 \mathrm{MPa}$ by 1000,3000 and $5000 \mathrm{yr}$, respectively. The upper most group of CCDFs emerges at approximately 1, which implies that initial intrusions at all times for the corresponding LHS elements are producing nonzero releases. Probabilities above are actually overestimates because spallings only gives releases for intrusions into CH-TRU waste. The CCDFs tend to emerge at lower probabilities because there is no guarantee that the specified time will actually have nonzero releases associated with it.

The primary determinant of the uncertainty in the CCDFs in Fig. 16 is the pressure conditions in repository (Fig. 11), with no spallings releases taking place at pressures less than $8 \mathrm{MPa}$. Given that the pressure is above $8 \mathrm{MPa}$, the uncertainty in the spallings release is determined by WPRTDIAM (Fig. 12).

To provide additional perspective, CCDFs for volume of material released by spallings (i.e., the quantity obtained from Table 3 when $C_{C H}$ is set to 1) can also be constructed (Fig. 18). Similarly to cuttings, the release of more than $10 \mathrm{~m}^{3}$ of material over $10,000 \mathrm{yr}$ is unlikely.

As was done for the cuttings CCDFs, a sensitivity analysis with rank-transformed data and the STEPWISE program can be performed on the expected spallings releases associated with each CCDF (Table 4). In carrying out the stepwise regression analyses (Sect. 3.5, Ref. 15) summarized in Table 4, a variable was required to be significant at the $0.02 \alpha$-level to enter a regression model and to remain significant at the $0.05 \alpha$-level to be retained in a regression model; further, bulk compressibility of anhydrite (ANHCOMP) and bulk compressibility of halite (HALCOMP) were not included as candidate variables for inclusion in a regression model due to the -0.99 rank correlations imposed on the variable pairs (ANHPRM, ANHCOMP) and (HALPRM, HALCOMP) (Sect. 7.2, Ref. $18)$.

The regressions for volume and normalized release are almost identical. The most important variable is the pointer variable for microbial degradation of cellulose (WMICDFLG), with expected releases tending to increase with increasing values of WMICDFLG due to the important influence of this variable on the pressure in the repository at the time of the first drilling intrusion (Fig. 18, Table 6, Ref. 16). Positive effects are also indicated for 
halite porosity $(H A L P O R)$, corrosion rate for steel under inundated conditions in the absence of $\mathrm{CO}_{2}(W G R C O R)$, logarithm of halite permeability ( $H A L P R M)$, increase in brine saturation of waste due to capillary forces (WASTWICK), and logarithm of anhydrite permeability (ANHPRM), with these effects resulting because increasing each of these variables tends to increase pressure in the repository at the time of the first drilling intrusion (Fig. 18, Table 6, Ref. 16). Negative effects are indicated for logarithm of borehole permeability (BHPRM) and WPRTDIAM. Increasing $B H P R M$ tends to reduce the pressure in the repository below the $8 \mathrm{MPa}$ threshold required for a spallings release (Fig. 32, Ref. 17) and thus to reduce or eliminate spallings releases due to intrusions subsequent to the initial intrusion into the repository. Increasing WPRTDIAM tends to decrease the size of the spallings release for a single intrusion (Fig. 12) and thus to reduce the expected releases.

The examination of scatterplots provides additional perspective on the factors that affect the expected spallings releases (Fig. 19). The tendency of the spallings release to increase with increasing microbial gas generation is readily seen in the corresponding scatterplot. Also, the zero spallings releases tend to be associated with the smaller values for $H A L P O R$. In contrast, the largest spallings releases tend to be associated with the smaller values for BHPRM and WPRTDIAM.

Another way to perform a sensitivity analysis on a distribution of CCDFs is by calculating partial rank correlation coefficients (PRCCs) between the exceedance probabilities associated with individual consequence values on the abscissa and the sampled variables (Sect. 3.5, Ref. 15). The resulting PRCCs can then be plotted above the consequence values at which they were calculated. The outcomes of an analysis of this type for the CCDFs for spallings volume (Fig. 18) and normalized release (Fig. 16) appear in Fig. 20, with PRCCs being shown for all variables whose PRCC exceeded 0.5 in absolute value at some point on the abscissa. The PRCCs were calculated with the PCCSRC program. ${ }^{49,50}$

As indicated by positive PRCCs, the exceedance probabilities for a given volume or normalized release tend to increase as each of WMICDFLG, HALPOR and WGRCOR increases. These positive effects result because increasing each of these variables tends to increase the pressure in the repository at the time of the first drilling intrusion. The negative effect for WPRTDIAM results because increasing particle diameter tends to decrease the size of the spallings releases associated with individual drilling intrusions (Fig. 12). The negative effect for BHPRM results because increasing $B H P R M$ tends to decrease the pressure in the repository after an initial drilling intrusion (Fig. 32, Ref. 17) and thus reduce the likelihood that second and subsequent drilling intrusions will produce spallings releases (Fig. 11).

The spallings releases for individual futures were constructed with the assumption that each intrusion could result in a spallings release (Table 3). However, releases after the first intrusion only occur if the pressure in the repository remains above $8 \mathrm{MPa}$. The pressure in the repository subsequent to an intrusion is very dependent on the borehole permeability (Fig. 32, Ref. 17). In the present analysis, there is no variation in the permeability in a 
borehole above the repository for plugging patterns 2 and 3; specifically, all boreholes for a given LHS element are assumed to have the same permeability. As the repository rapidly drops below $8 \mathrm{MPa}$ unless a borehole has a low permeability, it is probably unreasonable to assume that the pressure in the repository after multiple intrusions has the same value as after a single intrusion. Rather, once a higher permeability borehole occurs, the pressure would drop below $8 \mathrm{MPa}$ and no additional spallings releases would take place. Inclusion of this depressurization mechanism in the analysis would substantially reduce the spallings releases (Fig. 21).

\section{Discussion}

The 1996 WIPP PA incorporated four direct release modes to the surface environment: cuttings, cavings, spallings, and direct brine release. The cuttings, cavings and spallings release modes are described in this article; the direct brine release is described in another article. ${ }^{10}$ Cuttings and cavings releases occurred for all drilling intrusions through the repository and tended to dominate the direct releases. Spallings releases were sometimes as large as the cuttings and cavings releases when conditions that were conducive to spallings releases existed in the repository (e.g., sufficiently high pressures); however, spallings releases were often small or nonexistent when conditions existed in the repository that were not conducive to such releases. The direct brine releases tended to be much smaller than the cuttings and cavings releases. ${ }^{10}$

An extensive technical review of the conceptual models used in the 1996 WIPP PA was carried out by an independent review group. ${ }^{51}$ This group generally found the models used in the 1996 WIPP PA to be acceptable representations of the processes under consideration but expressed concern about the appropriateness of the spallings model. In response, an investigation of the spallings phenomenon was initiated, with this investigation coming to the conclusion that the spallings model used in the 1996 WIPP PA is unlikely to have underestimated the size of the spallings releases. ${ }^{52}$ At present, work is underway to develop a more realistic spallings model for use in future WIPP PAs. ${ }^{53}$

The 1996 WIPP PA incorporates two distinct treatments of uncertainty: stochastic uncertainty (Sect. 3, Ref. 6; Ref. 7) and subjective uncertainty (Sect. 5, Ref. 6; Ref. 8), with stochastic uncertainty being characterized by a probability space $\left(\mathrm{S}_{s t}, \& s t, p_{s t}\right)$ and subjective uncertainty being characterized by a probability space $\left(\mathrm{S}_{s u}, \& s u\right.$, $p_{s u}$ ). Simple random sampling is used to propagate the effects of stochastic uncertainty through the analysis (Sect. 4 , Ref. 6; Ref. 7), and Latin hypercube sampling is used to propagate the effects of subjective uncertainty through the analysis (Sect. 5, Ref. 6; Ref. 8).

Latin hypercube sampling creates a mapping from uncertain analysis inputs (i.e., elements $\mathbf{x}_{s u}$ of $\mathrm{S}_{s u}$ ) to analysis results. This mapping then forms the basis for both uncertainty and sensitivity analyses (Sect. 5, Ref. 6; Ref. 15). Uncertainty and sensitivity analysis results for individual drilling intrusions are presented for cuttings and cavings releases (Sect. 4) and also spallings releases (Sect. 9). 
The uncertainty in the cuttings and cavings releases is smaller than the uncertainty in the spallings releases and derives from the uncertainty in the shear strength of the waste (WTAUFAIL). The shear strength of the waste only affects the cavings release; none of the variables contained in $\mathbf{x}_{s u}$ affected the cuttings release. In previous PAs for the WIPP, uncertainty in drill bit diameter has had a significant effect on the uncertainty in the cuttings release; 54,55 however, in consistency with guidance by the EPA that current drilling practices in the Delaware Basin should be assumed in assessing compliance with 40 CFR 191 (Ref. 3), the 1996 WIPP PA assumed a drill bit diameter of 12.25 in, which is the drill bit diameter typically used in oil and gas exploration in the Delaware Basin (Sect. 7.0, Ref. 19). As a result, there was no uncertainty in the amount of original, uncompacted waste removed as cuttings by a drilling intrusion, although the amount of radionuclide removed to the surface did vary depending on the time of the drilling intrusion and the particular waste streams intersected.

The uncertainty in the spallings release was dominated by whether or not a release occurred, with no spallings releases occurring when the repository pressure at the time of a drilling intrusion was less than $8 \mathrm{MPa}$ (i.e., the pressure exerted by a column of brine-saturated drilling fluid at the depth of the repository; see Ref. 43 . Thus, the uncertainty in whether or not a spallings release will occur for an initial intrusion into the repository is dominated by the variables that affect repository pressure under undisturbed conditions (i.e., WMICDFLG, WGRCOR, WASTWICK and HALPOR; see Sect. 4, Ref. 16). Similarly, the uncertainty in whether or not a spallings release will occur for a second or subsequent drilling intrusion into the repository is dominated by the variable(s) that affect repository pressure subsequent to a drilling intrusion (i.e., BHPRM; see Sect. 4, Ref. 17). Repository pressure tends to be the same throughout the repository subsequent to a drilling intrusion (Figs. 28, 29, Ref. 17); thus, the individual waste panels do not behave as isolated entities and the size of second and subsequent spallings releases for a given element $\mathbf{x}_{s t}$ of $\mathrm{S}_{s t}$ tends to be little affected by when and where the associated drilling intrusions occur. Given that a spallings release occurs, the size of this release is determined by waste particle diameter (WPRTDIAM; see Fig. 12). Although pressure may remain an important part of future spallings models, ${ }^{52,53}$ it is possible that WPRTDIAM will not be a part of these models.

The 1996 WIPP PA used random sampling to determine CCDFs due to cuttings and cavings releases (Fig. 6) and also spallings releases (Fig. 16) for comparison with the boundary line specified by the EPA in 40 CFR 191 (i.e., to integrate over $\mathrm{S}_{s t}$; see Sect. 3, Ref. 6; Ref. 7). These CCDFs were constructed with a random sample of size $n S=$ 10,000 from the probability space $\left(\mathrm{S}_{s t}, \& s t, p_{s t}\right)$ for stochastic uncertainty (see Table 5, Ref. 7). To make the construction of the CCDFs computationally tractable, a relatively small number of calculations were performed with the cuttings, cavings, and spalling models; then, various interpolation and algebraic procedures were used to obtain the results actually used in the construction of CCDFs (see Table 1 and Eq. (31) for cuttings and cavings, and Tables 2 and 3 for spallings). This Monte Carlo procedure for CCDF construction ${ }^{56}$ provides a way to use results from the cuttings, cavings and spallings models in $\mathrm{CCDF}$ construction without having to run these models for every element 
$\mathbf{x}_{s t}$ of $\mathrm{S}_{s t}$ used in CCDF construction. A similar approach was used in the systems prioritization methodology (SPM) implemented for the WIPP in the mid-1990s (Refs. 57, 58).

Subjective uncertainty as characterized by the probability space $\left(\mathrm{S}_{s u}, \&_{s u}, p_{s u}\right)$ gives rise to a distribution of CCDFs for the cuttings and cavings release (Fig. 6) and also for the spallings release (Fig. 16), with each CCDF in Figs. 6 and 16 arising from one LHS element from $S_{s u}$. The proximity of these distributions to the boundary line specified by the EPA in 40 CFR 191 then provides a measure of confidence with respect to whether or not it is felt that this regulation will be met. As neither estimated distribution of CCDFs has even a single CCDF that crosses the boundary line, a high degree of confidence is indicated that the containment requirements in 40 CFR 191 are indeed being met.

The distributions of CCDFs generated by Latin hypercube sampling from $\left(\mathrm{S}_{s u}, \&_{s u}, p_{s u}\right)($ Figs. 6, 16) are only approximations to what these distributions really are (i.e., the distributions that would be obtained if it was possible to integrate over $\left(\mathrm{S}_{s t}, \&_{s t}, p_{s t}\right)$ and $\left(\mathrm{S}_{s u}, \&{ }_{s u}, p_{s u}\right)$ without error). To obtain an indication of the possible numerical error in using Latin hypercube sampling to integrate over $\left(\mathrm{S}_{s u}, \&{ }_{s u}, p_{s u}\right)$, the analysis was performed with three replicated LHSs of size 100 each (Sect. 8, Ref. 8). Use of these three replicated samples indicates that the estimation of the CCDF distributions is quite stable for the sample sizes in use (i.e., 100 for the individual replicates and 300 for the 3 pooled replicates) (Figs. 7, 17) and that no significant (i.e., compliance assessment altering) change in the interpretation of the CCDF distributions would result from use of a larger sample size.

Due to the small size of the direct brine releases ${ }^{10}$ and the absence of any releases due to transport through the Culebra Dolomite, ${ }^{12}$ the CCDFs from the 1996 WIPP PA for comparison with the EPA release limits in 40 CFR 191 are dominated by the cuttings and cavings components of the total release, with a sometimes substantial but typically smaller contribution from the spallings component. ${ }^{13}$ Without changing the drilling rate mandated by the EPA in 40 CFR 194 (Sect. 2, Ref. 7), the CCDF due to cuttings alone represents a release level below which no reduction is possible.

As already indicated, the initial drilling intrusion into the repository almost always results in a pressure of less than $8 \mathrm{MPa}$ throughout the repository. The 1996 WIPP PA did not consider drilling intrusions into the operations and experimental areas of the repository (Regions 26, 27, Fig. 1, Ref. 9). As the operations and experimental areas contain no waste, initial intrusions into these areas would have resulted in no direct releases while, at the same time, depressurizing the repository and thus preventing spallings releases due to subsequent intrusions into the repository. As a result, the inclusion of drilling intrusions into the operations and experimental areas would have tended to move the spallings CCDFs away from the EPA boundary line. However, as the total release tends to be dominated by the cuttings and cavings components (Figs. 6, 16), the inclusion of this depressurization mechanism would not have a substantial effect on the location of the CCDFs for total release to the accessible environment. ${ }^{13}$ 


\section{Acknowledgment}

Work performed for Sandia National Laboratories (SNL), which is a multiprogram laboratory operated by Sandia Corporation, a Lockheed Martin Company, for the United States Department of Energy under contract DE-AC04-94AL85000. Review provided at SNL by M. Chavez, C. Crawfordand M.S. Tierney. Editorial support provided by L. Harrison, T. Allen and H. Radke of Tech Reps, Inc. 


\section{References}

1. U.S. Environmental Protection Agency, 40 CFR Part 191: Environmental Standards for the Management and Disposal of Spent Nuclear Fuel, High-Level and Transuranic Radioactive Wastes; Final Rule, Federal Register, $1985,50(182) 38066-38089$.

2. U.S. Environmental Protection Agency, 40 CFR Part 191: Environmental Radiation Protection Standards for the Management and Disposal of Spent Nuclear Fuel, High-Level and Transuranic Radioactive Wastes; Final Rule, Federal Register, 1993, 58(242), 66398-66416.

3. U.S. Environmental Protection Agency, 40 CFR Part 194: Criteria for the Certification and Re-Certification of the Waste Isolation Pilot Plant's Compliance With the 40 CFR Part 191 Disposal Regulations; Final Rule, Federal Register, 1996, 61(28), 5224-5245.

4. Howard, B.A., Crawford, M.B., Galson, D.A., Marietta, M.G., Regulatory Basis for the Waste Isolation Pilot Plant Performance Assessment, Reliability Engineering and System Safety (in this issue).

5. U.S. Department of Energy, Title 40 CFR Part 191 Compliance Cerification Application for the Waste Isolation Pilot Plant, DOE/CAO-1996-2184, Volumes I-XXI, U.S. Department of Energy, Carlsbad Area Office, Carlsbad, NM, 1996.

6. Helton, J.C., Anderson, D.R., Basabilvazo, G., Jow, H.-N., \& Marietta, M.G., Conceptual Structure of the 1996 Performance Assessment for the Waste Isolation Pilot Plant, Reliability Engineering and System Safety (in this issue).

7. Helton, J.C., Davis, F.J., \& Johnson, J.D., Characterization of Stochastic Uncertainty in the 1996 Performance Assessment for the Waste Isolation Pilot Plant, Reliability Engineering and System Safety (in this issue).

8. Helton, J.C., Martell, M.-A., \& Tierney, M.S., Characterization of Subjective Uncertainty in the 1996 Performance Assessment for the Waste Isolation Pilot Plant, Reliability Engineering and System Safety (in this issue).

9. Vaughn, P., Bean, J.E., Helton, J.C., Lord, M.E., MacKinnon, R.J., \& Schreiber, J.D., Representation of TwoPhase Flow in the Vicinity of the Repository in the 1996 Performance Assessment for the Waste Isolation Pilot Plant, Reliability Engineering and System Safety (in this issue).

10. Stoelzel, D.M., O'Brien, D.G., Garner, J.W., Helton, J.C., Johnson, J.D., \& Smith, L.N., Direct Releases to the Surface and Associated Complementary Cumulative Distribution Functions in the 1996 Performance Assessment for the Waste Isolation Pilot Plant: Direct Brine Release, Reliability Engineering and System Safety (in this issue).

11. Stockman, C.T., Garner, J.W., Helton, J.C., Johnson, J.D., Shinta, A., \& Smith, L.N., Radionuclide Transport in the Vicinity of the Repository and Associated Complementary Cumulative Distribution Functions in the 1996 Performance Assessment for the Waste Isolation Pilot Plant, Reliability Engineering and System Safety (in this issue).

12. Ramsey, J.L., Blaine, R., Garner, J.W., Helton, J.C., Johnson, J.D., Smith, L.N., \& Wallace, M., Radionuclide and Colloid Transport in the Culebra Dolomite and Associated Complementary Cumulative-Distribution 
Functions in the 1996 Performance Assessment for the Waste Isolation Pilot Plant, Reliability Engineering and System Safety (in this issue).

13. Helton, J.C., Anderson, D.R., Basabilvazo, G., Jow, H.-N., \& Marietta, M.G., Summary Discussion of the 1996 Performance Assessment for the Waste Isolation Pilot Plant, Reliability Engineering and System Safety (in this issue).

14. McKay, M.D., Beckman, R.J., \& Conover, W.J., A Comparison of Three Methods for Selecting Values of Input Variables in the Analysis of Output from a Computer Code, Technometrics, 1979, 21(2), 239-245.

15. Helton, J.C., Uncertainty and Sensitivity Analysis Techniques for Use in Performance Assessment for Radioactive Waste Disposal, Reliability Engineering and System Safety, 1993, 42(2-3), 327-367.

16. Helton, J.C., Bean, J.E., Economy, K., Garner, J.W., MacKinnon, R.J., Miller, J., Schreiber, J.D., \& Vaughn, P, Uncertainty and Sensitivity Analysis for Two-Phase Flow in the Vicinity of the Repository in the 1996 Performance Assessment for the Waste Isolation Pilot Plant: Undisturbed Conditions, Reliability Engineering and System Safety (in this issue).

17. Helton, J.C., Bean, J.E., Economy, K., Garner, J.W., MacKinnon, R.J., Miller, J., Schreiber, J.D., \& Vaughn, P., Uncertainty and Sensitivity Analysis for Two-Phase Flow in the Vicinity of the Repository in the 1996 Performance Assessment for the Waste Isolation Pilot Plant: Disturbed Conditions, Reliability Engineering and System Safety (in this issue).

18. Helton, J.C., Bean, J.E., Berglund, J.W., Davis, F.J., Economy, K., Garner, J.W., Johnson, J.D., MacKinnon, R.J., Miller, J., O’Brien, D.G., Ramsey, J.L., Schreiber, J.D., Shinta, A., Smith, L.N., Stoelzel, D.M., Stockman, C., \& Vaughn, P., Uncertainty and Sensitivity Analysis Results Obtained in the 1996 Performance Assessment for the Waste Isolation Pilot Plant, SAND98-0365, Sandia National Laboratories, Albuquerque, NM, 1998.

19. Berglund, J. W., Analysis Package for the Cuttings and Spalling Calculations (Tasks 5 and 6) of the Performance Assessment Analyses Supporting the Compliance Certification Application., Sandia WIPP Central Files WPO \# 40521, Sandia National Laboratories, Albuquerque, NM, 1996.

20. Tierney, M., Emplaced Height of Remote Handled Waste in CCDFGF Model, WIPP Data Entry Form. Sandia WIPP Central Files WPO \# 38744, Sandia National Laboratories, Albuquerque, NM, 1996.

21. Helton, J.C., Anderson, D.R., Baker, B.L., Bean, J.E., Berglund, J.W., Beyeler, W., Garner, J.W., Iuzzolino, H.J., Marietta, M.G., Rechard, R.P., Roache, P.J., Rudeen, D.K., Schreiber, J.D., Swift, P.N., Tierney, M.S., \& Vaughn, P., Effect of Alternative Conceptual Models in a Preliminary Performance Assessment for the Waste Isolation Pilot Plant, Nuclear Engineering and Design, 1995, 154(3), 251-344.

22. Broc, R., (ed.), Drilling Mud and Cement Slurry Rheology Manual, Gulf Publishing Company, Houston, TX, 1982.

23. Darley, H.C.H., A Laboratory Investigation of Borehole Stability, Journal of Petroleum Technology, Trans AIME, $1969,246,883-892$.

24. Walker, R.E. \& Holman, W.E., Computer Program Predicting Drilling-Fluid Performance, Oil and Gas Journal, March 29, 1971, 69(13), 80-90. 
25. WIPP PA (Performance Assessment), Preliminary Comparison with 40 CFR Part 191, Subpart B for the Waste Isolation Pilot Plant, SAND91-0893/1-4, Volumes 1-4, Sandia National Laboratories, Albuquerque, NM, 19911992.

26. Rechard, R.P., Iuzzolino, H., \& Sandha, J.S., Data Used in Preliminary Performance Assessment of the Waste Isolation Pilot Plant (1990), SAND89-2408, Sandia National Laboratories, Albuquerque, NM, 1990.

27. Berglund, J.W, Mechanisms Governing the Direct Removal of Wastes from the Waste Isolation Pilot Plant Repository Caused by Exploratory Drilling, SAND92-7295, Sandia National Laboratories, Albuquerque, NM, 1992.

28. Walker, R.E., Hydraulic Limits are Set by Flow Restrictions, Oil and Gas Journal, 1976, 74(40), 86-90.

29. Oldroyd, J.G., Non-Newtonian Effects in Steady Motion of Some Idealized Elastico-Viscous Liquids, Proceedings of the Royal Society of London, Series A. Mathematical and Physical Sciences, 1958, 245(1241), 278-297.

30. Savins, J.G. \& Wallick, G.C., Viscosity Profiles, Discharge Rates, Pressures, and Torques for a Rheologically Complex Fluid in a Helical Flow, A.I.Ch.E. Journal, 1996, 12 (2), 357-363.

31. Whittaker, A., ed., Theory and Application of Drilling Fluid Hydraulics. International Human Resources Development Corporation, Boston, MA, 1985.

32. Streeter, V.L., Fluid Mechanics, 2nd ed., McGraw-Hill, New York, NY, 1958.

33. WIPP PA (Performance Assessment), Preliminary Performance Assessment for the Waste Isolation Pilot Plant, December 1992, SAND92-0700/1-5, Volumes 1-5, Sandia National Laboratories, Albuquerque, NM, 19921993.

34. Abdul Khader, M.H., \& Rao, H.S., Flow Through Annulus with Large Radial Clearance, American Society of Civil Engineers, Journal of the Hydraulics Division, 1974, 100, HY1, 25-39.

35. Bilgen, E., Boulos, R. \& Akgungor, A.C., Leakage and Frictional Characteristics of Turbulent Helical Flow In Fine Clearance, Journal of Fluids Engineering, 1973, 95(4), 493-497.

36. WIPP PA, CUTTINGS_S, Version 5.03, Version Date 4/22/96, User's Manual, Sandia WIPP Central Files WPO \# 37765, Sandia National Laboratories, Albuquerque, NM, 1996.

37. U.S. Department of Energy, Transuranic Waste Baseline Inventory Report, DOE/CAO-95-1121, Revision 2, 1995.

38. Sanchez, L.C., Liscum-Powell, J., Rath, J.S., \& Trellue, H.R., WIPP PA Analysis Report for EPAUNI: Estimating Probability Distribution of EPA Unit Loading in the WIPP Repository for Performance Assessment Calculations, Version 1.01, Sandia WIPP Central Files WPO \# 43843, Sandia National Laboratories, Albuquerque, NM, 1997.

39. Sanchez, L., Drez, P.E., \& Rath, J.S., Radioactive and Nonradioactive Waste Intended for Disposal at the Waste Isolation Pilot Plant, Reliability Engineering and System Safety (in this issue). 
40. Iman, R.L. \& Conover, W.J., The Use of the Rank Transform in Regression, Technometrics, 1979, 21(4), 499 509.

41. Iman, R.L., Davenport, J.M., Frost, E.L., and Shortencarier, M.J., Stepwise Regression with PRESS and Rank Regression (Program User's Guide), SAND79-1472, Sandia National Laboratories, Albuquerque, NM, 1980.

42. WIPP PA (Performance Assessment), WIPP PA User's Manual for STEPWISE, Version 2.20, Document Version 1.00, Sandia WIPP Central Files WPO \# 27768, Sandia National Laboratories, Albuquerque, NM, 1995.

43. Stoelzel, D.M. \& O'Brien, D.G., Analysis Package for the BRAGFLO Direct Release Calculations (Task 4) of the Performance Assessment Analyses Supporting the Compliance Certification Application, Sandia WIPP Central Files WPO \#40520, Sandia National Laboratories, Albuquerque, NM, 1996.

44. Lenke, L.R., Berglund, J.W., \& Cole, R.A., Blowout Experiments using Fine Grained Silica Sands in an Axisymmetric Geometry, Contractor Report 1996/7/32250, New Mexico Engineering Research Institute, University of New Mexico, March 1996.

45. Cheremisinoff, N. P. \& Cheremisinoff, P.N., Hydrodynamics of Gas-Solids Fluidization, Gulf Publishing Co., Houston, TX, 1984.

46. Fox, R.W. \& McDonald, A.T., Introduction to Fluid Mechanics, John Wiley \& Sons, New York, NY, 1973.

47. Obert, E.F., Thermodynamics, McGraw-Hill, New York, NY, 1948.

48. Binder, R.C., Advanced Fluid Mechanics, Prentice Hall, Inc., Englewood Cliffs, NJ, 1958.

49. Iman, R.L., Shortencarier, M.J., \& Johnson, J.D., A FORTRAN 77 Program and User's Guide for the Calculation of Partial Correlation and Standardized Regression Coefficients, NUREG/CR-4122, SAND850044, Sandia National Laboratories, Albuquerque, NM, 1985.

50. Gilkey, A.P., PCCSRC, Version 2.21, User's Manual, Document Version 1.0, Sandia WIPP Central Files WPO \#30732, Sandia National Laboratories, Albuquerque, NM, 1995.

51. Wilson, C., Porter, D., Gibbons, B., Oswald, E., Sjoblem, G., \& Caporuscio, F., Final Waste Isolation Pilot Plant Conceptual Models Peer Review Report (July 1996, Sandia WIPP Central Files WPO \#41805). Waste Isolation Pilot Plant Conceptual Models Supplementary Peer Review Report (December 1996, Sandia WIPP Central Files WPO \#43153). Waste Isolation Pilot Plant Second Supplementary Peer Review Report (January 1997, Sandia WIPP Central Files WPO \#44536). U.S. Department of Energy, Carlsbad Area Office, Office of Regulatory Compliance, Carlsbad, NM, 1996-1997.

52. Hansen, F.D., Knowles, M.K., Thompson, T.W., Gross, M., McLennan, J.D., \& Schatz, J.F., Description and Evaluation of a Mechanistically Based Conceptual Model for Spall, SAND97-1369, Sandia National Laboratories, Albuquerque, NM, 1997.

53. Knowles, M.K., Hansen, F.D., Thompson, T.W. Gross, M.B., \& Schatz, J.F., Review and Perspectives on Spallings Releases in the 1996 Performance Assessment for the Waste Isolation Pilot Plant, Reliability Engineering and System Safety (in this issue). 
54. Helton, J.C., Garner, J.W., Marietta, M.G., Rechard, R.P., Rudeen, D.K., \& Swift, P.N., Uncertainty and Sensitivity Analysis Results Obtained in a Preliminary Performance Assessment for the Waste Isolation Pilot Plant, Nuclear Science and Engineering, 1993, 114(4), 286-331.

55. Helton, J.C., Anderson, D.R., Baker, B.L., Bean, J.E., Berglund, J.W., Beyeler, W., Economy, K., Garner, J.W., Hora, S.C., Iuzzolino, H.J., Knupp, P., Marietta, M.G., Rath, J., Rechard, R.P., Roache, P.J., Rudeen, D.K., Salari, K., Schreiber, J.D., Swift, P.N., Tierney, M.S., \& Vaughn, P., Uncertainty and Sensitivity Analysis Results Obtained in the 1992 Performance Assessment for the Waste Isolation Pilot Plant, Reliability Engineering and System Safety, 1996, 51 (1), 53-100.

56. Helton, J.C. \& Shiver, A.W., A Monte Carlo Procedure for the Construction of Complementary Cumulative Distribution Functions for Comparison with the EPA Release Limits for Radioactive Waste Disposal, Risk Analysis, 1996, 16(1), 43-55.

57. Helton, J.C., Beyeler, W., \& Hora, S.C., Conceptual Basis of a Systems Prioritization Methodology for the Waste Isolation Pilot Plant, Reliability Engineering and System Safety, 1997, 57(3), 203-222.

58. Helton, J.C., Anderson, D.R., Baker, B.L., Bean, J.E., Berglund, J.W., Beyeler, W., Blaine, R., Economy, K., Garner, J.W., Hora, S.C., Lincoln, R.C., Marietta, M.G., Mendenhall, F.T., Prindle, N.H., Rudeen, D.K., Schreiber, J.D., Shiver, A.W., Smith, L.N., Swift, P.N., \& Vaughn, P., Computational Implementation of a Systems Prioritization Methodology for the Waste Isolation Pilot Plant: A Preliminary Example, Reliability Engineering and System Safety, 1997, 57(3), 223-266. 
Figure Captions

Fig. 1. Detail of rotary drill string adjacent to drill bit (Fig. 7.3, Vol. 2, Ref. 25; Fig. 13, Ref. 21).

Fig. 2. Concentration (EPA units $/ \mathrm{m}^{3}$ ) of $\mathrm{CH}$ - and $\mathrm{RH}$-TRU waste.

Fig. 3. Distribution of original (i.e., uncompacted) volume removed due to cuttings and cavings by a single drilling intrusion through CH-TRU waste.

Fig. 4. Scatterplot for volume of material removed from repository due to cuttings and cavings by a single drilling intrusion through $\mathrm{CH}-\mathrm{TRU}$ waste versus shear resistance for erosion (WTAUFAIL).

Fig. 5. Distribution of normalized release to accessible environment for cuttings and cavings removal from $\mathrm{CH}$ TRU waste due to variation in intersected waste streams. Results calculated with median volume from Fig. 3 (i.e., $0.508 \mathrm{~m}^{3}$ ), $38.6 \%$ of removed volume assumed to be CH-TRU waste, and a sample of size 10,000 at each time.

Fig. 6. Distribution of CCDFs for normalized release to accessible environment over 10,000 yr due to cuttings and cavings: (6a) CCDFs for replicate $\mathrm{R} 1$, and (6b) mean and percentile curves obtained by pooling replicates $\mathrm{R} 1, \mathrm{R} 2$ and $\mathrm{R} 3$ (right frame).

Fig. 7. Outcome of replicated sampling for distribution of CCDFs for normalized release to the accessible environment over 10,000 yr due to cuttings and cavings: (7a) mean and percentile curves for individual replicates, and ( $7 b)$ confidence intervals (Cls) on mean curve obtained from the three replicates (right frame).

Fig. 8. Scatterplot for expected cuttings and cavings release for individual CCDFs versus WTAUFAIL.

Fig. 9. Distribution of CCDFs for volume of material removed to accessible environment over $10,000 \mathrm{yr}$ due to cuttings and cavings: (9a) CCDFs for replicate $\mathrm{R} 1$, and (9b) mean and percentile curves obtained by pooling replicates R1, R2 and R3 (right frame).

Fig. 10. Distribution of original (i.e., uncompacted) volume removed (Frame 10a) and normalized release (Frame $10 \mathrm{~b}$ ) due to spallings for a single drilling intrusion into a previously unintruded repository that encounters CH-TRU waste.

Fig. 11. Scatterplots for volume of material removed from repository due to spallings resulting from a single drilling intrusion at $5000 \mathrm{yr}$ into a previously unintruded repository that passes through $\mathrm{CH}-\mathrm{TRU}$ waste in a lower waste panel versus pressure (WAS_PRES) in repository.

Fig. 12. Scatterplots for volume of material removed from repository due to spallings resulting from a single drilling intrusion into a previously unintruded repository at $5000 \mathrm{yr}$ that passes through CH-TRU waste in a lower waste panel versus diameter of particles available for removal by spallings (WPRTDIAM).

Fig. 13. Three dimensional scatterplots for volume of material removed from repository due to spallings resulting from a single drilling intrusion at $5000 \mathrm{yr}$ into a previously unintruded repository that passes through $\mathrm{CH}-$ TRU waste in a lower waste panel versus pressure (WAS_PRES) and diameter of particles available for removal by spallings (WPRTDIAM).

Fig. 14. Distribution of original (i.e., uncompacted) volume removed and normalized release due to spallings for the second drilling intrusion into CH-TRU waste after an initial E1 intrusion at 350 or $1000 \mathrm{yr}$. 
Fig. 15. Distribution of original (i.e., uncompacted) volume removed and normalized release due to spallings for the second drilling intrusion into $\mathrm{CH}-\mathrm{TRU}$ waste after an initial E2 intrusion at 350 or $1000 \mathrm{yr}$.

Fig. 16. Distribution of CCDFs for normalized release to accessible environment over $10,000 \mathrm{yr}$ due to spallings: (16a) CCDFs for replicate R1, and (16b) mean and percentile curves obtained by pooling replicates R1, R2 and R3.

Fig. 17. Outcome of replicated sampling for distribution of CCDFs for normalized release to the accessible environment over 10,000 yr due to spallings: (17a) mean and percentile curves for individual replicates, and $(17 \mathrm{~b})$ confidence intervals (CIs) on mean curve obtained from the three replicates.

Fig. 18. Distribution of CCDFs for volume of material removed to accessible environment over 10,000 yr due to spallings: (18a) CCDFs for replicate R1, and (18b) mean and percentile curves obtained by pooling replicates $R 1, R 2$ and $R 3$.

Fig. 19. Scatterplots for expected normalized releases associated with individual CCDFs for spallings versus WMICDFLG, HALPOR, BHPRM, and WPRTDIAM.

Fig. 20. Sensitivity analysis based on PRCCs for CCDFs for volume removed (Frame 20a) and normalized release (Frame 20b) due to spallings.

Fig. 21. Distribution of CCDFs obtained with replicate R1 for normalized release to accessible environment over $10,000 \mathrm{yr}$ due to spallings with the assumption that spallings releases will only take place for the first two drilling intrusions into the repository. 


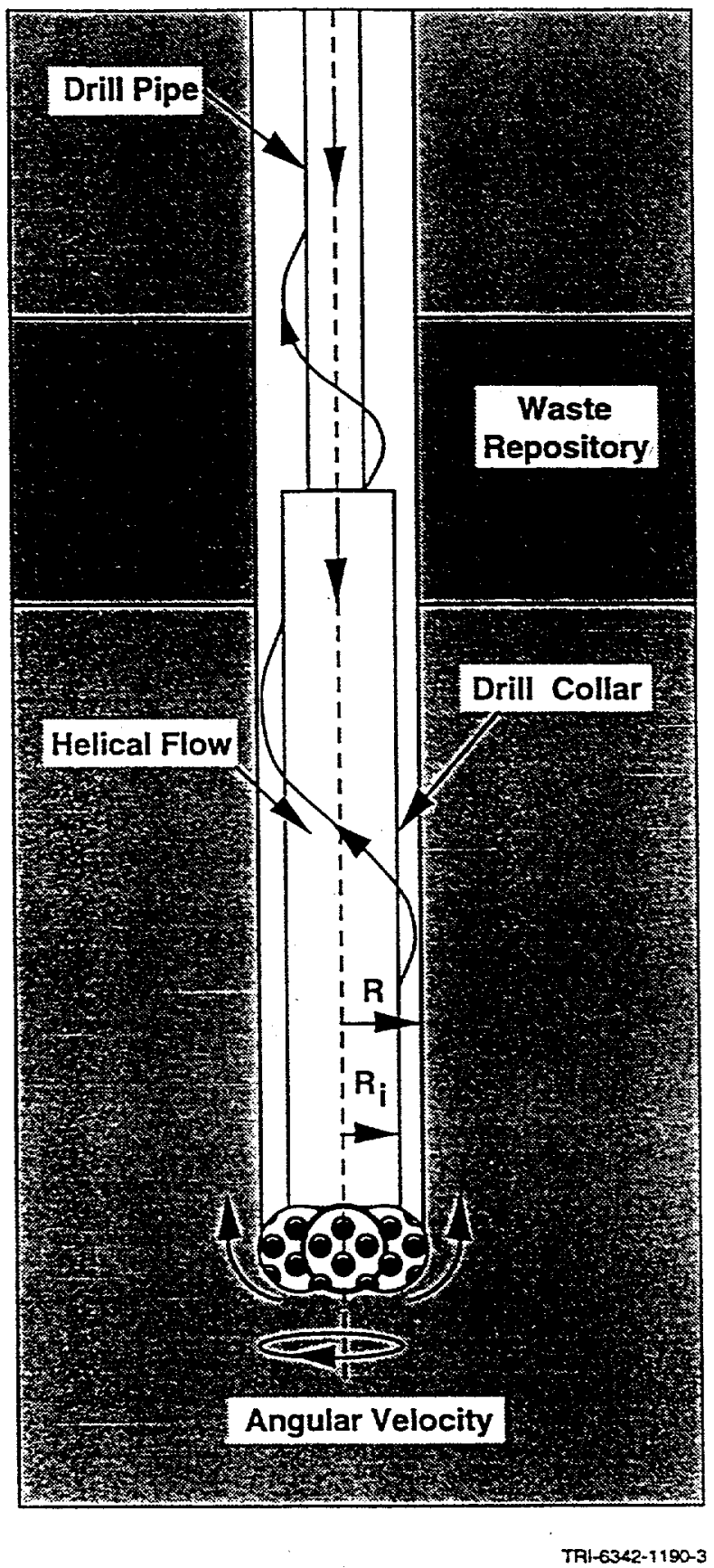

Fig. 1. Detail of rotary drill string adjacent to drill bit (Fig. 7.3, Vol. 2, Ref. 25; Fig. 13, Ref. 21). 


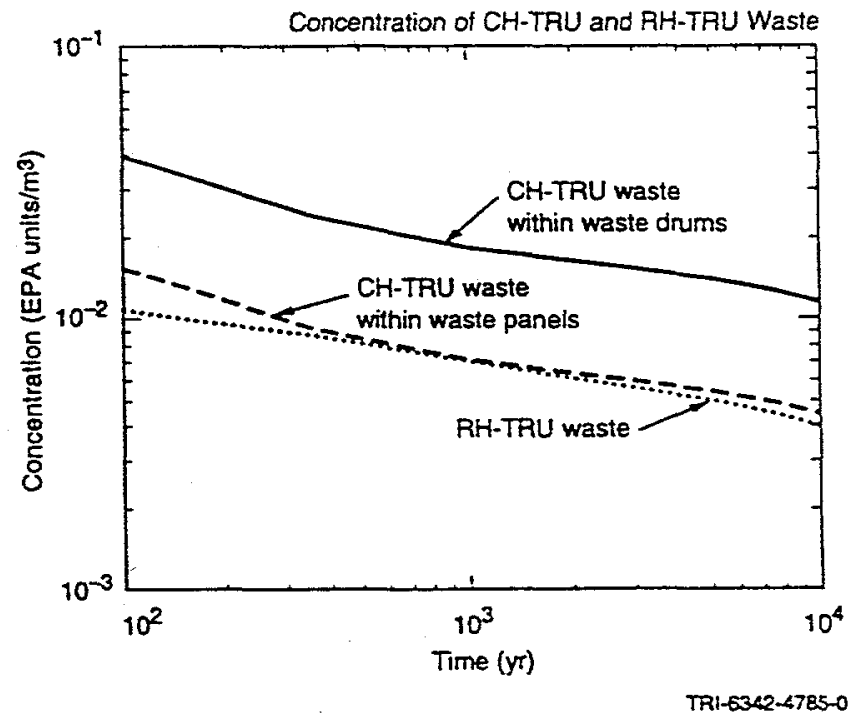

Fig. 2. Concentration (EPA units $/ \mathrm{m}^{3}$ ) of $\mathrm{CH}$ - and RH-TRU waste.

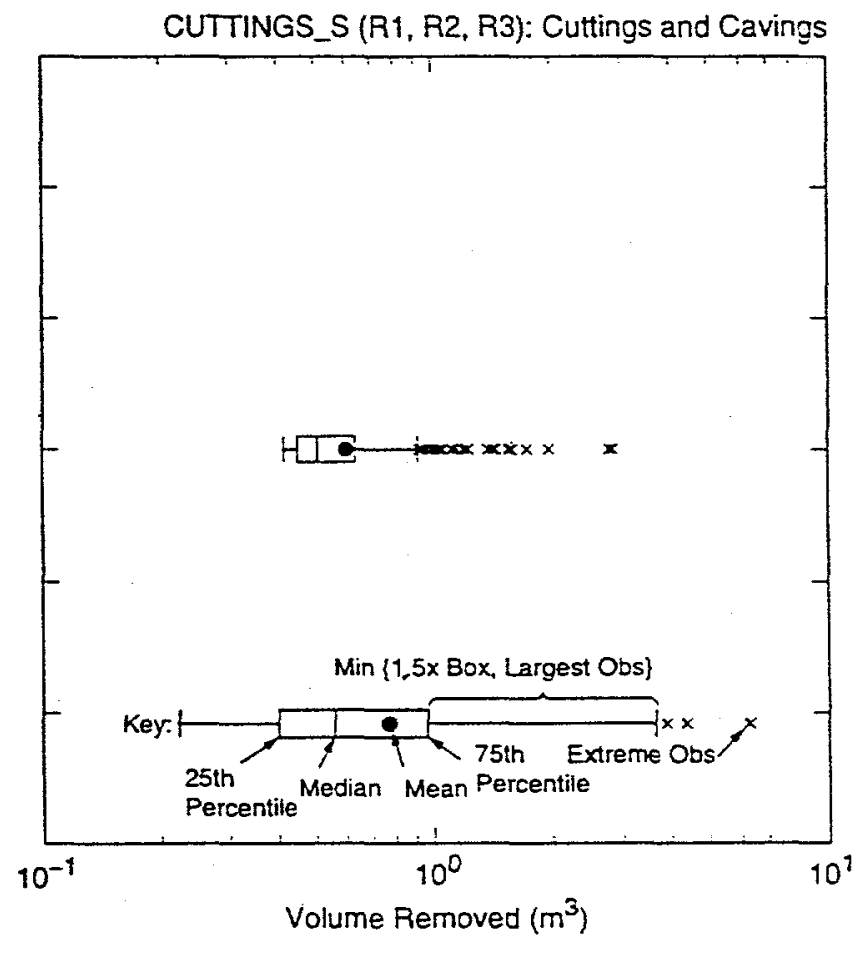

TRI- $53<2-4786-1$

Fig. 3. Distribution of original (i.e., uncompacted) volume removed due to cuttings and cavings by a single drilling intrusion through $\mathrm{CH}-\mathrm{TRU}$ waste. 


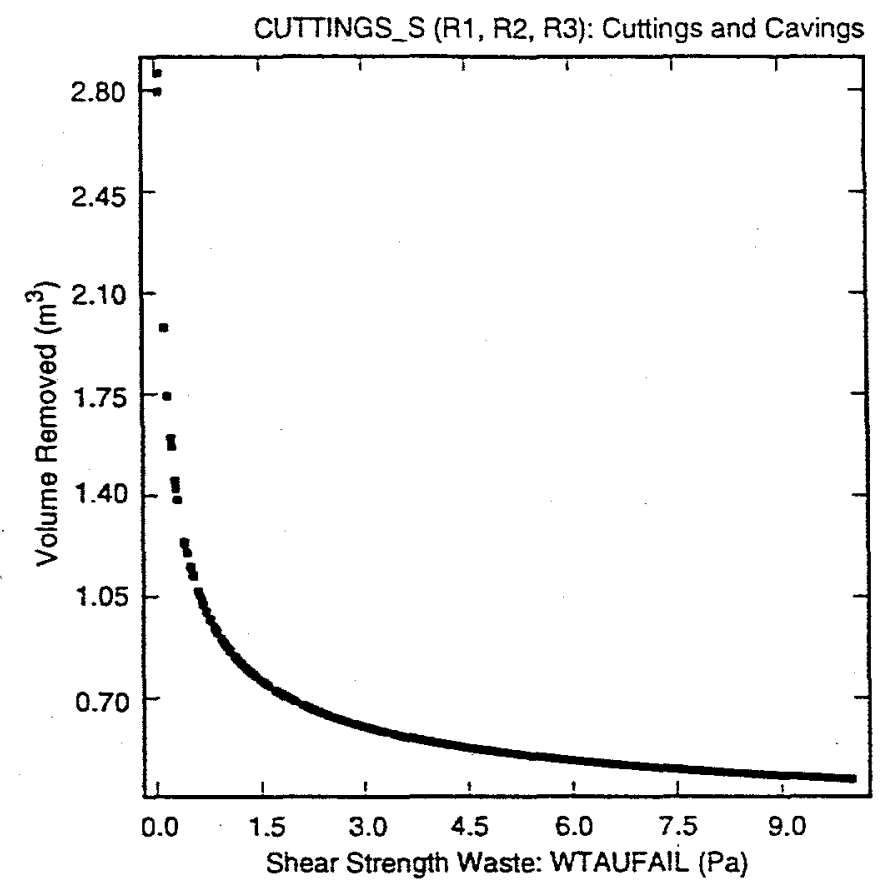

TลI-6342-4784-0

Fig. 4. Scatterplot for volume of material removed from repository due to cuttings and cavings by a single drilling intrusion through $\mathrm{CH}-\mathrm{TRU}$ waste versus shear resistance for erosion (WTAUFAIL).

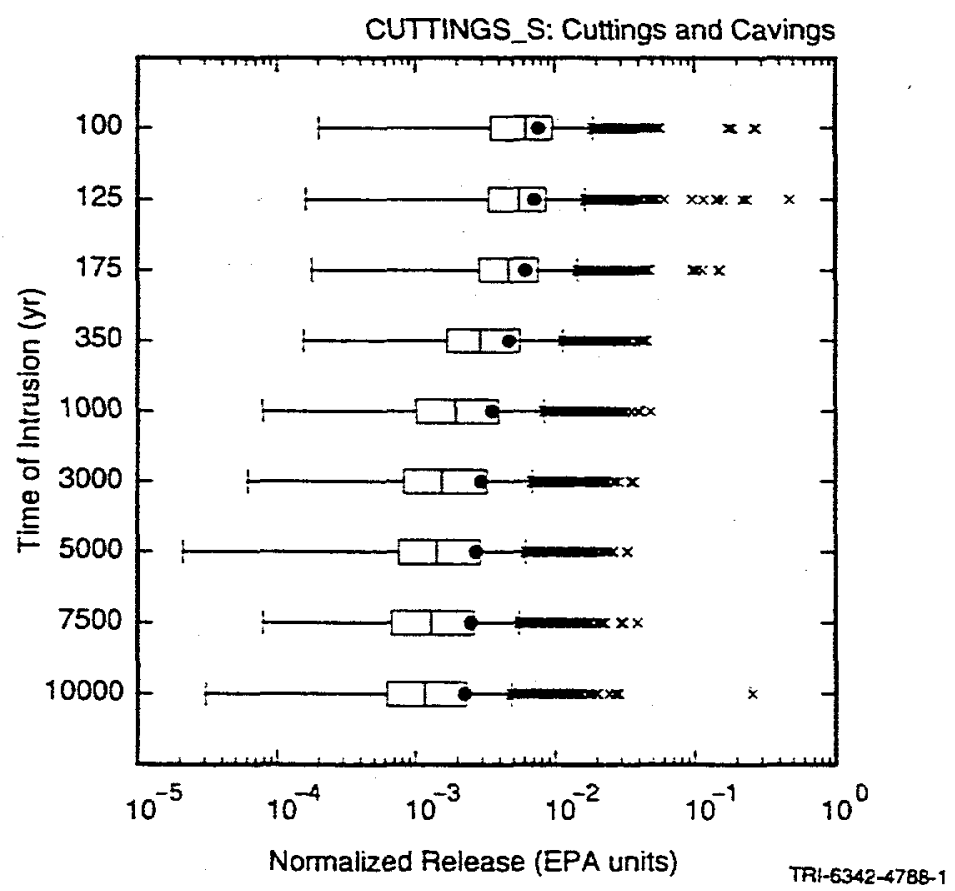

Fig. 5. Distribution of normalized release to accessible environment for cuttings and cavings removal from $\mathrm{CH}$ TRU waste due to variation in intersected waste streams. Results calculated with median volume from Fig. 3 (i.e., $0.508 \mathrm{~m}^{3}$ ), $38.6 \%$ of removed volume assumed to be CH-TRU waste, and a sample of size 10,000 at each time. 

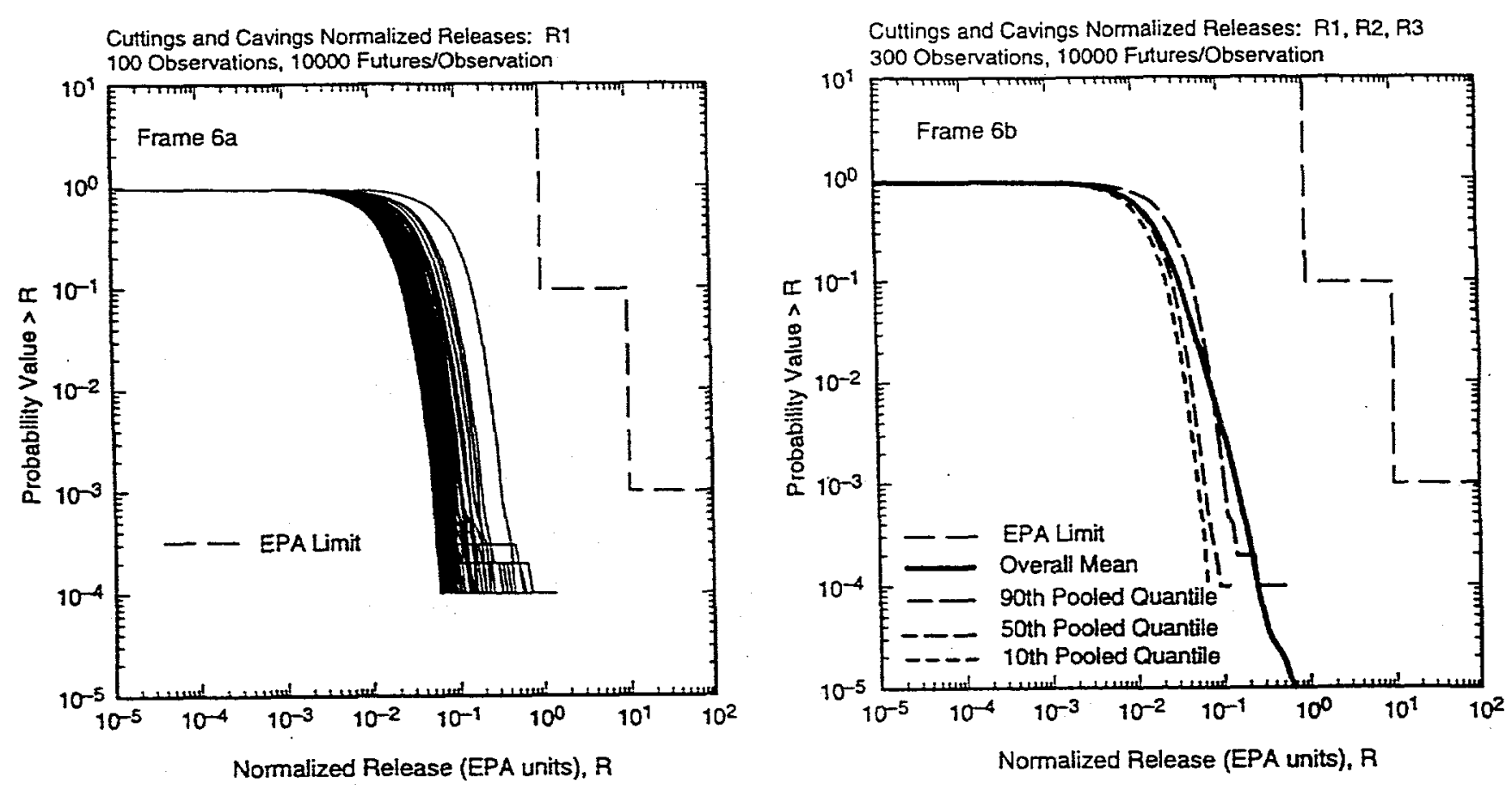

Th1-6342-4982-0

Fig. 6. Distribution of CCDFs for normalized release to accessible environment over $10,000 \mathrm{yr}$ due to cuttings and cavings: (6a) CCDFs for replicate $\mathrm{R} 1$, and (6b) mean and percentile curves obtained by pooling replicates $\mathrm{R} 1, \mathrm{R} 2$ and $\mathrm{R} 3$.
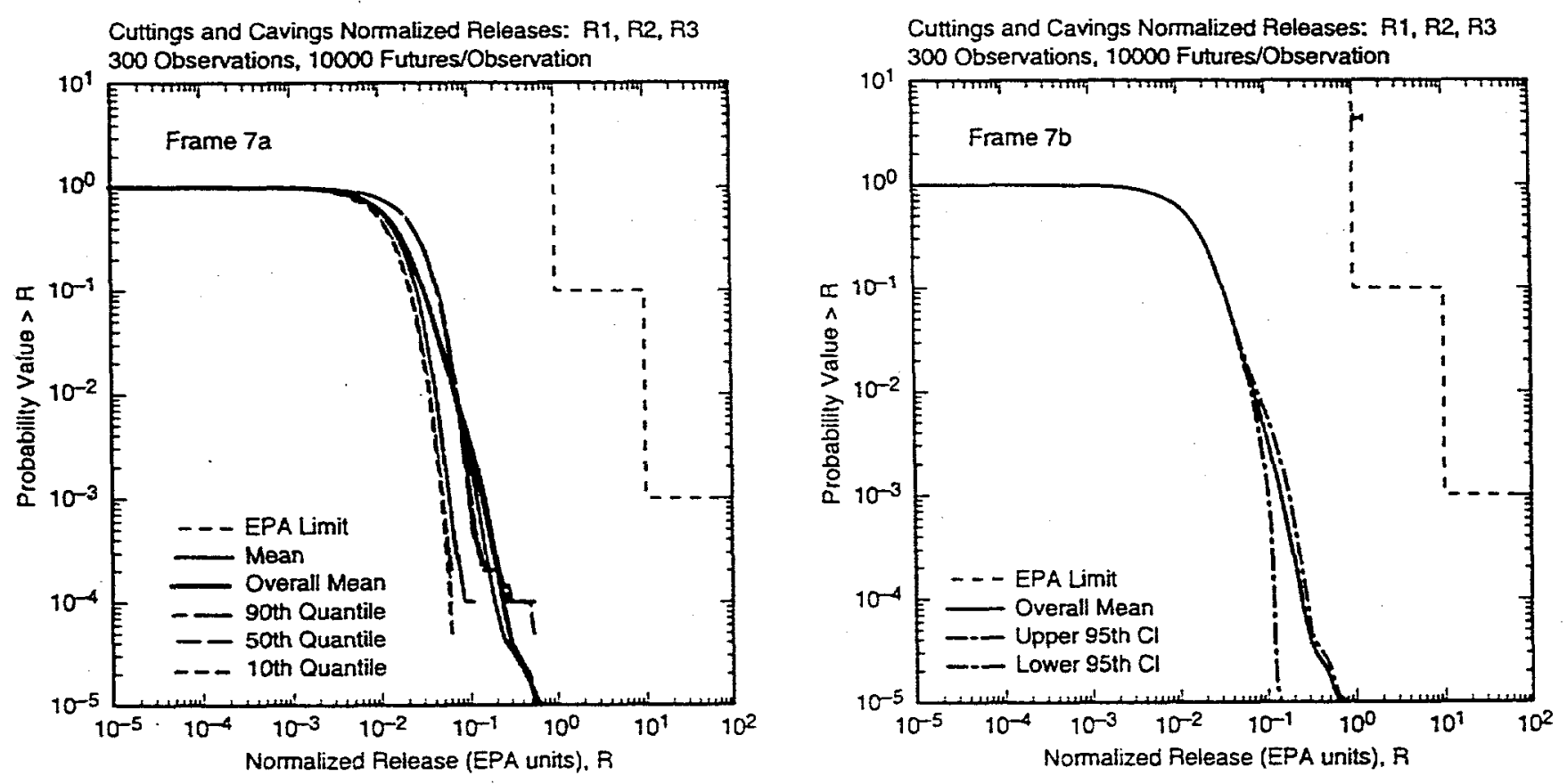

TR1-6342-4983-0

Fig. 7. Outcome of replicated sampling for distribution of CCDFs for normalized release to the accessible environment over 10,000 yr due to cuttings and cavings: (7a) mean and percentile curves for individual replicates, and ( $7 \mathrm{~b}$ ) confidence intervals (CIs) on mean curve obtained from the three replicates. 


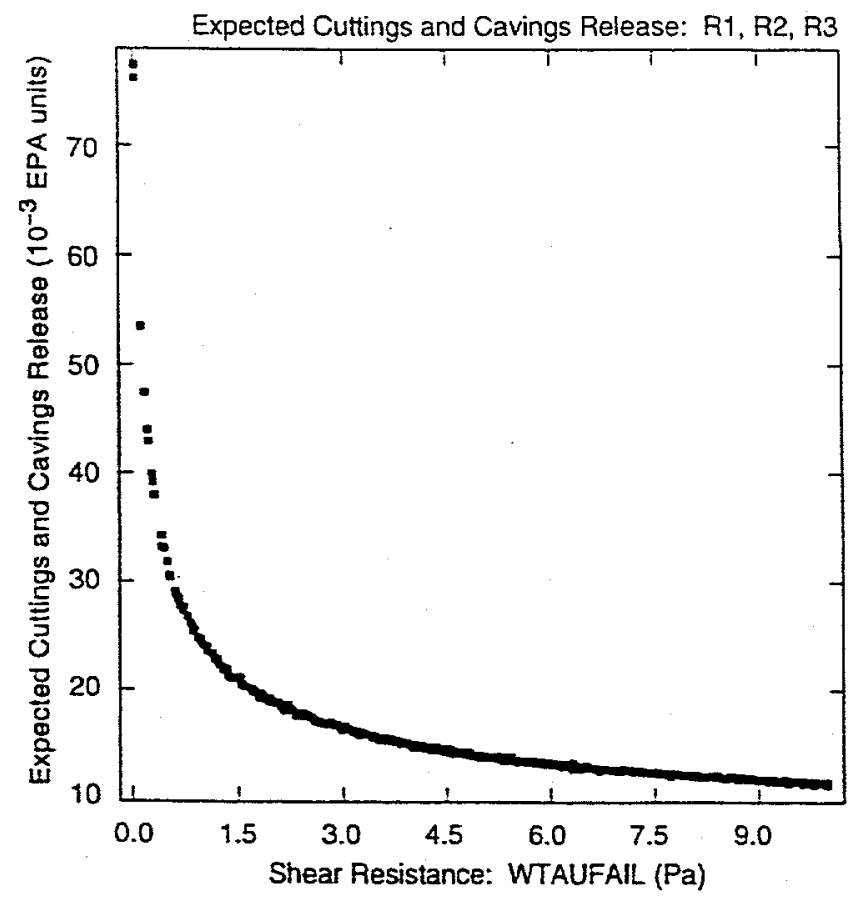

TR1-5342-5:50-0

Fig. 8. Scatterplot for expected cuttings and cavings release for individual CCDFs versus WTAUFAIL.
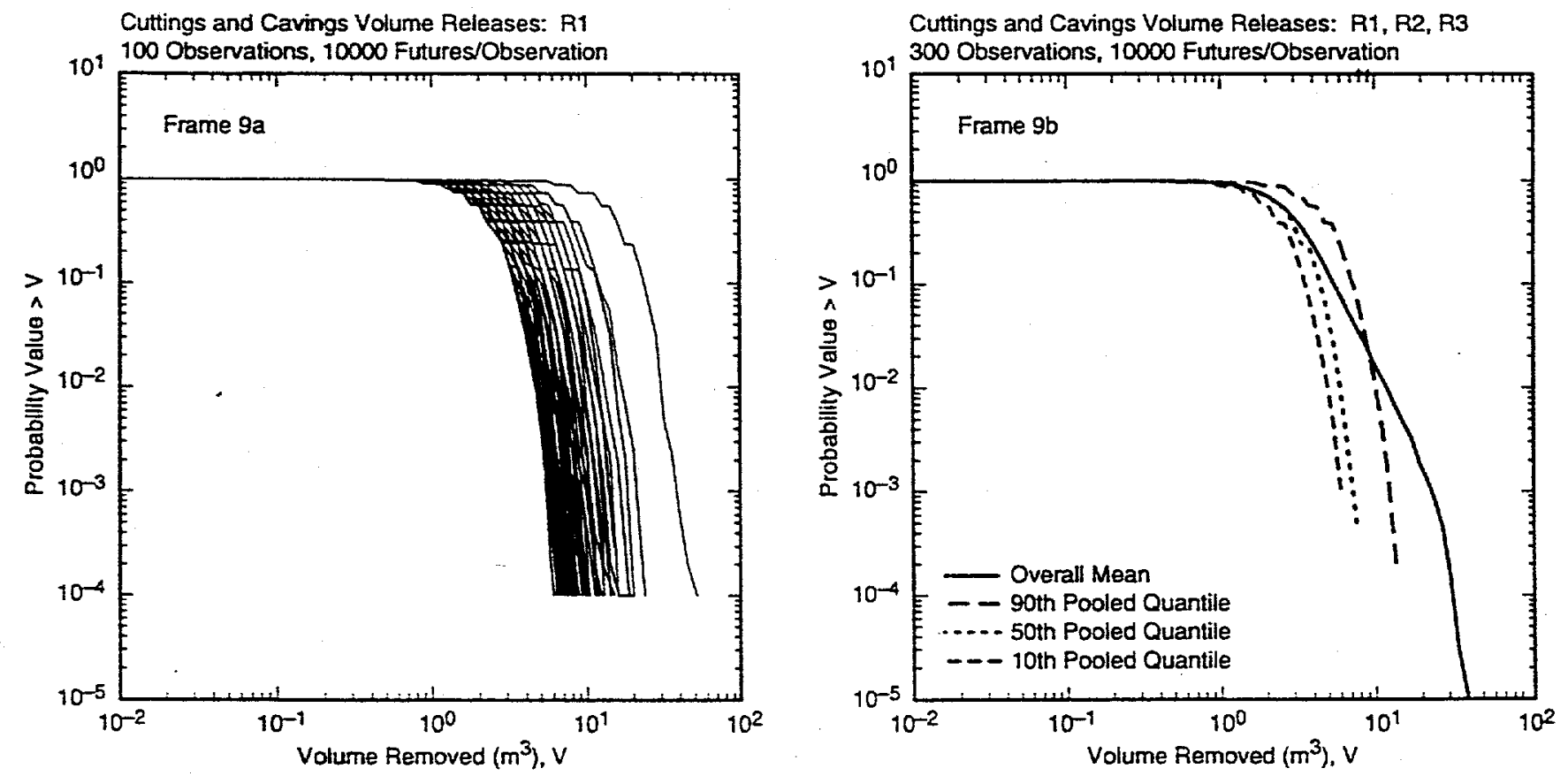

TRI-6342-4984-0

Fig. 9. Distribution of CCDFs for volume of material removed to accessible environment over 10,000 yr due to cuttings and cavings: (9a) CCDFs for replicate Rl, and (9b) mean and percentile curves obtained by pooling replicates $\mathrm{R} 1, \mathrm{R} 2$ and $\mathrm{R} 3$. 

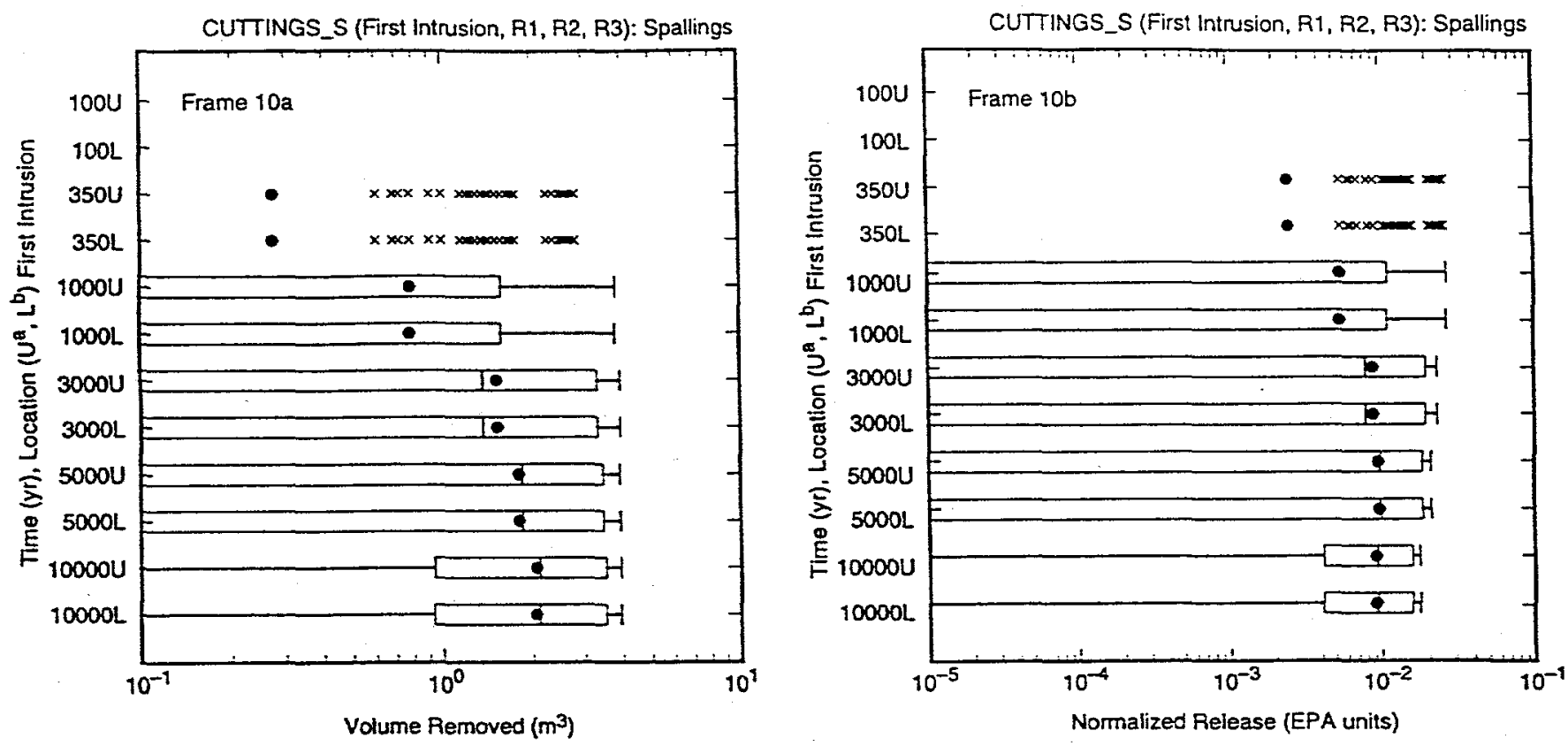

a Signifies Intrusion into an Upper (U) Waste Panel

$b_{L}$ Signifies Intrusion into an Lower (L) Waste Panel

TRI- $-6342-4773-2$

Fig. 10. Distribution of original (i.e., uncompacted) volume removed (Frame 10a) and normalized release (Frame $10 \mathrm{~b}$ ) due to spallings for a single drilling intrusion into a previously unintruded repository that encounters CH-TRU waste.

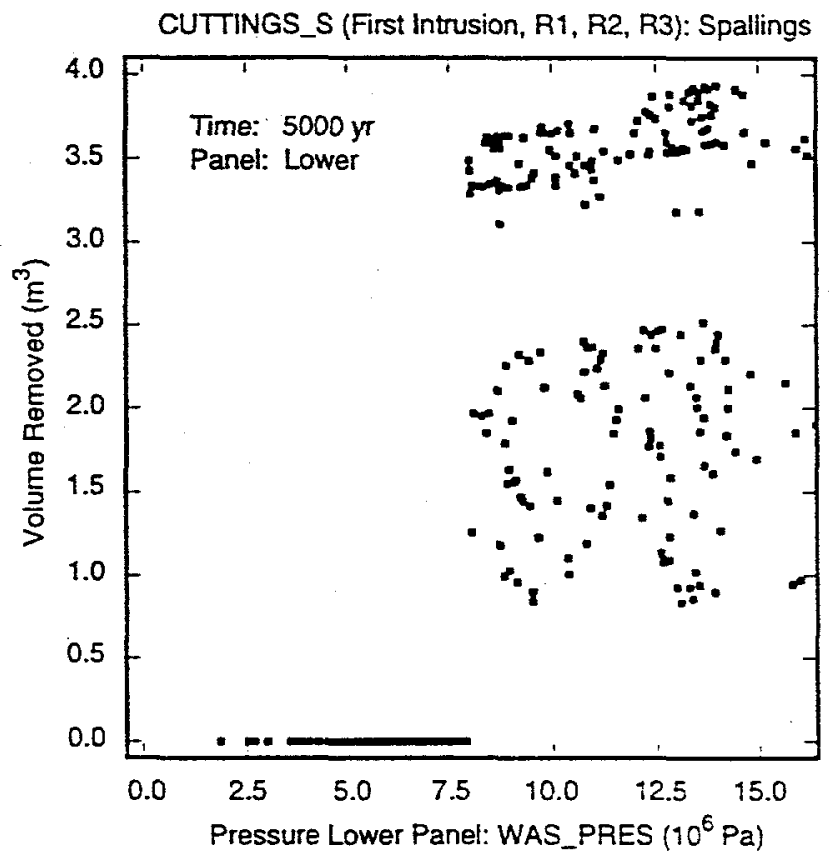

Fig. 11. Scatterplots for volume of material removed from repository due to spallings resulting from a single drilling intrusion at $5000 \mathrm{yr}$ into a previously unintruded repository that passes through CH-TRU waste in a lower waste panel versus pressure (WAS_PRES) in repository. 


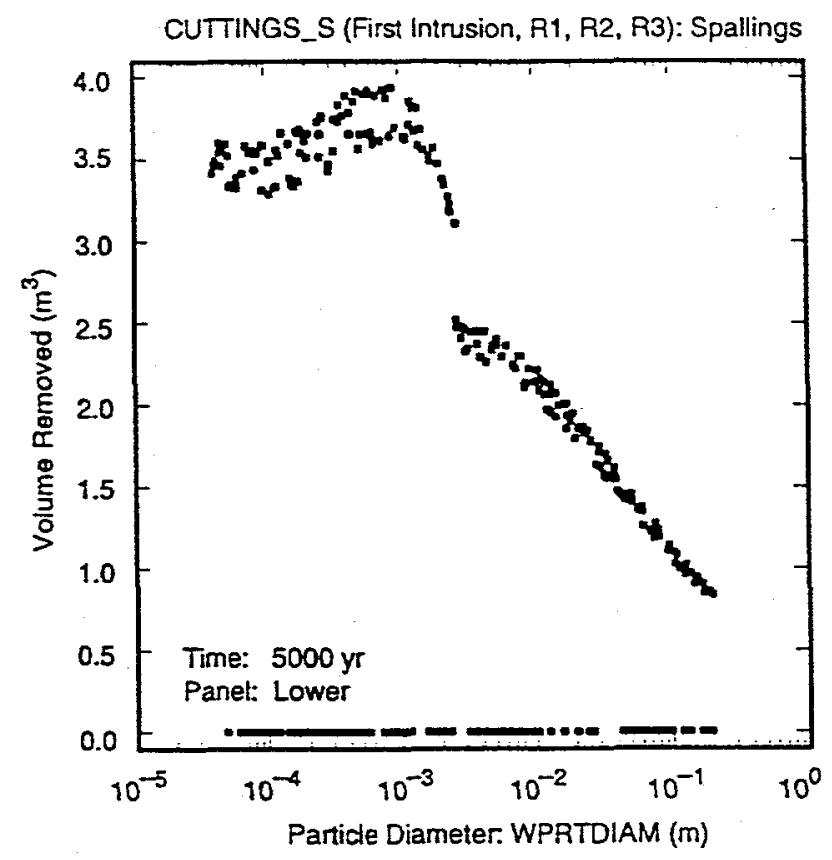

TRI-5342-4774-00

Fig. 12. Scatterplots for volume of material removed from repository due to spallings resulting from a single drilling intrusion into a previously unintruded repository at 5000 yr that passes through $\mathrm{CH}-\mathrm{TRU}$ waste in a lower waste panel versus diameter of particles available for removal by spallings (WPRTDIAM).

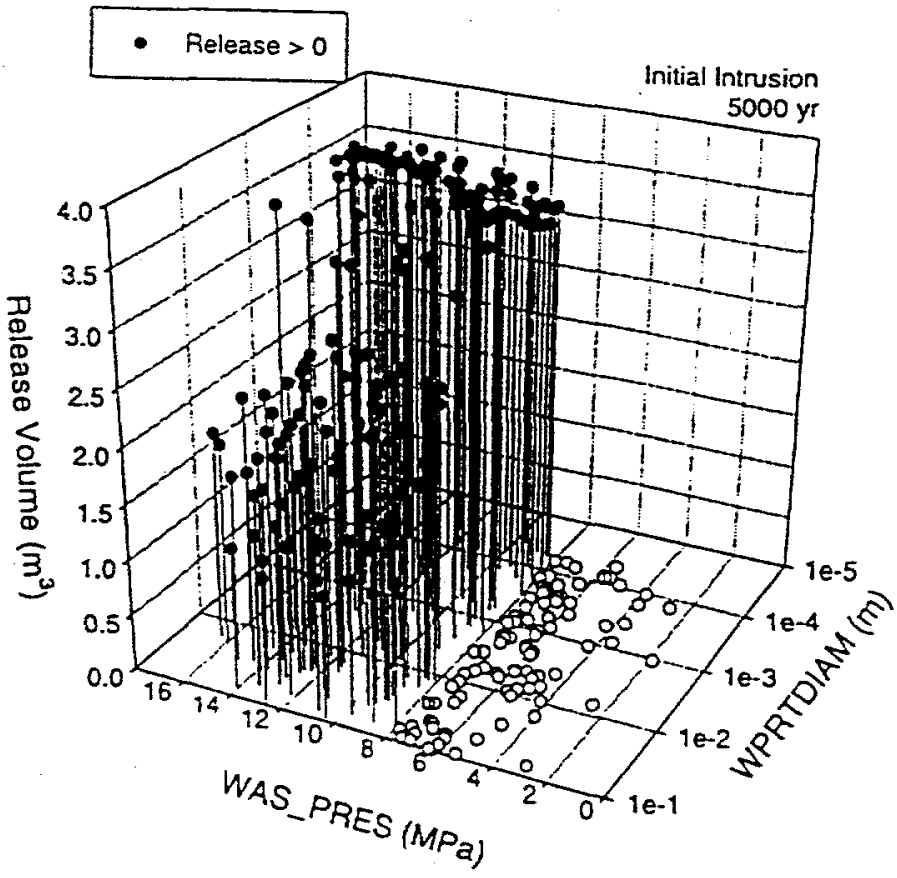

Fig. 13. Three dimensional scatterplots for volume of material removed from repository due to spallings resulting from a single drilling intrusion at $5000 \mathrm{yr}$ into a previously unintruded repository that passes through $\mathrm{CH}$ TRU waste in a lower waste panel versus pressure (WAS_PRES) and diameter of particles available for removal by spallings (WPRTDIAM). 

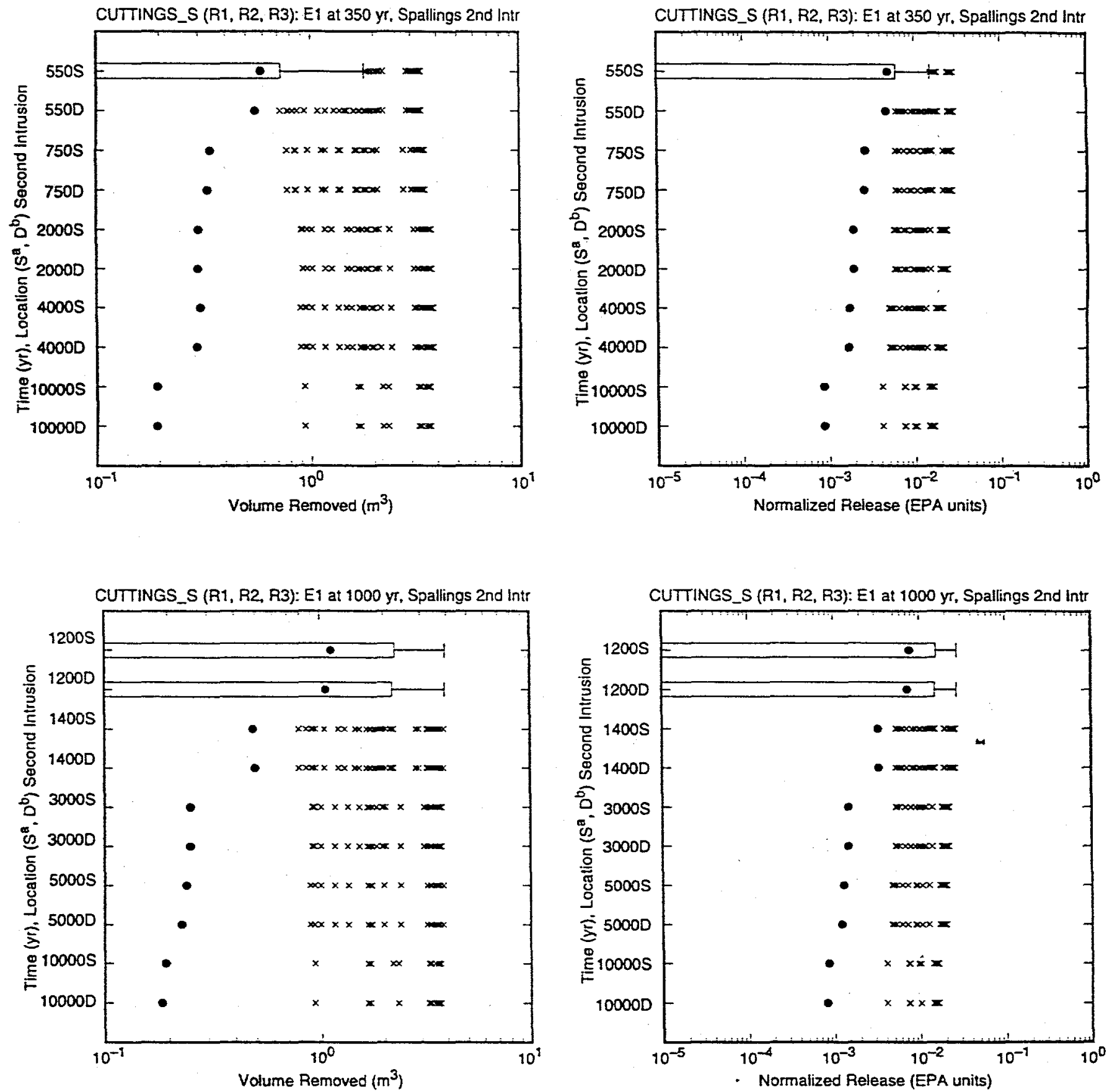

${ }^{2} S$ Signifies Second Intrusion Occurs in Same (S) Waste Panel as First intrusion

Do Signifies Second Intrusion Occurs in Different (D) Waste Panel than First Intusion

TRI-6342-4782-0

Fig. 14. Distribution of original (i.e., uncompacted) volume removed and normalized release due to spallings for the second drilling intrusion into CH-TRU waste after an initial E1 intrusion at 350 or $1000 \mathrm{yr}$. 

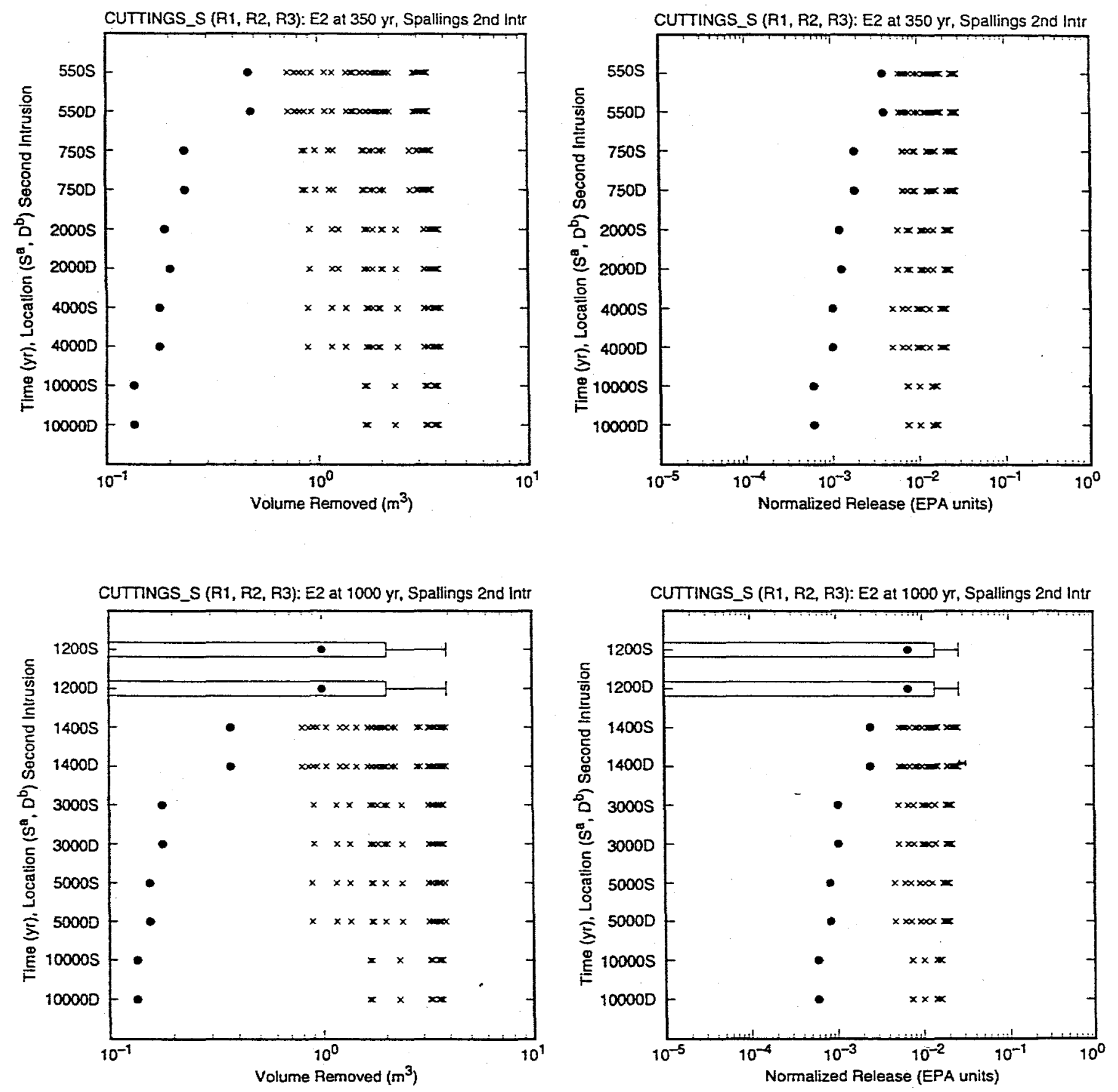

as Signifies that the second intrusion occurs in the same (S) waste panel as the first

b Signifies that the second intrusion occurs in a different (D) waste panel than the first

TA1-6342-4763-0

Fig. 15. Distribution of original (i.e., uncompacted) volume removed and normalized release due to spallings for the second drilling intrusion into CH-TRU waste after an initial E2 intrusion at 350 or $1000 \mathrm{yr}$. 

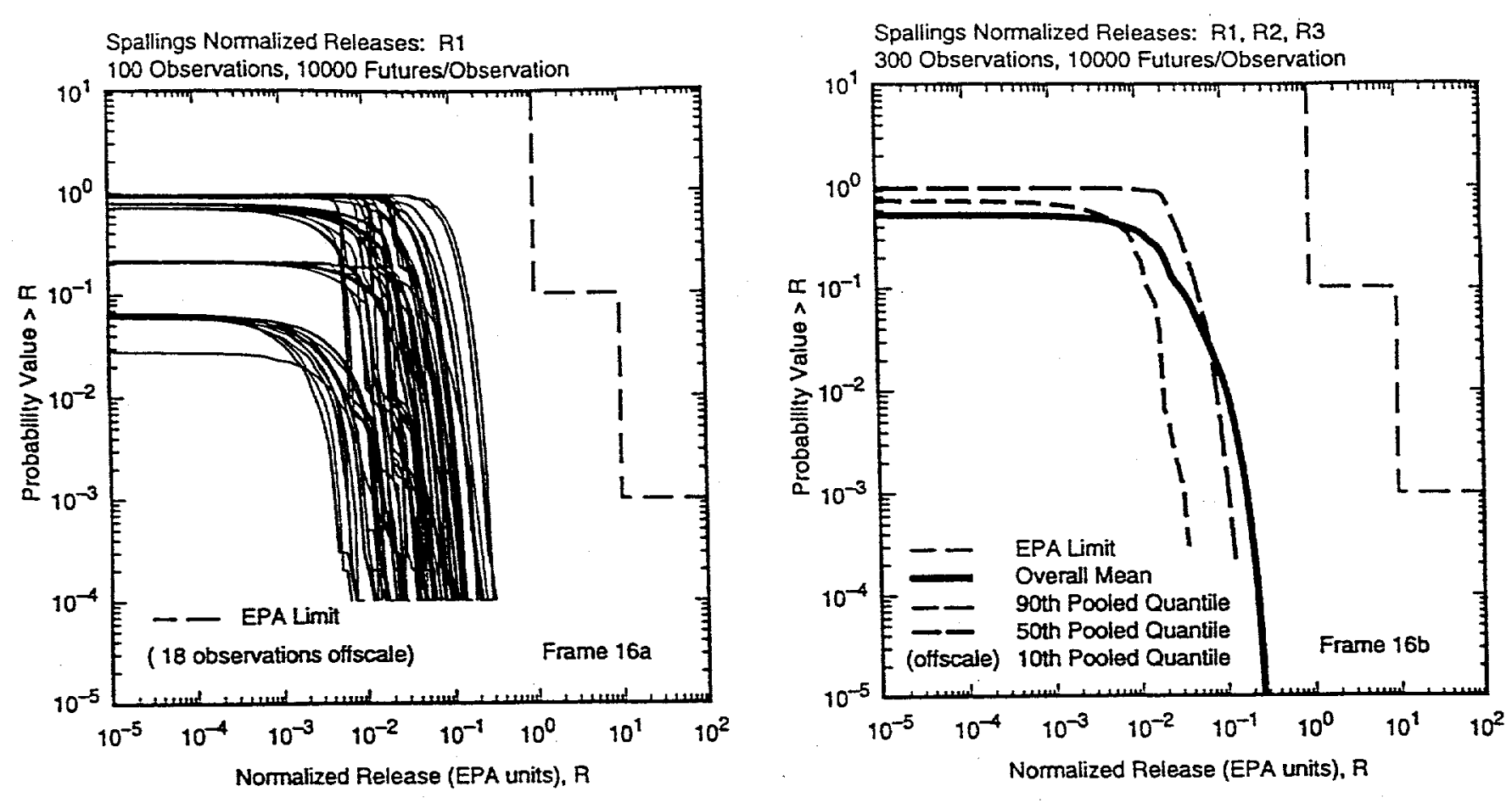

TFII-6342-4985-0

Fig. 16. Distribution of CCDFs for normalized release to accessible environment over $10,000 \mathrm{yr}$ due to spallings: (16a) CCDFs for replicate R1, and (16b) mean and percentile curves obtained by pooling replicates R1, R2 and R3.
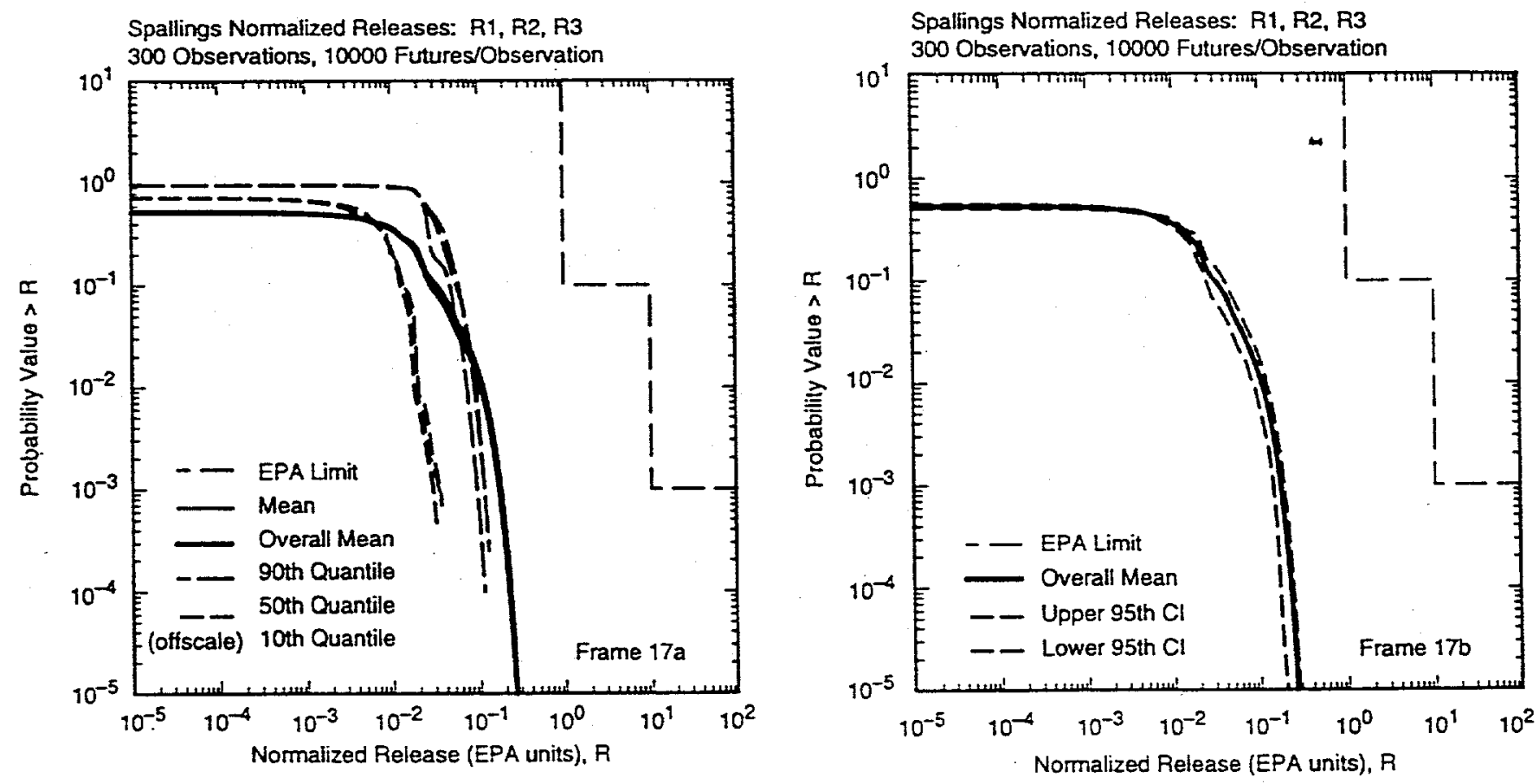

TA1-6342-4986-0

Fig. 17. Outcome of replicated sampling for distribution of CCDFs for normalized release to the accessible environment over 10,000 yt due to spallings: (17a) mean and percentile curves for individual replicates, and (17b) confidence intervals (CIs) on mean curve obtained from the three replicates. 

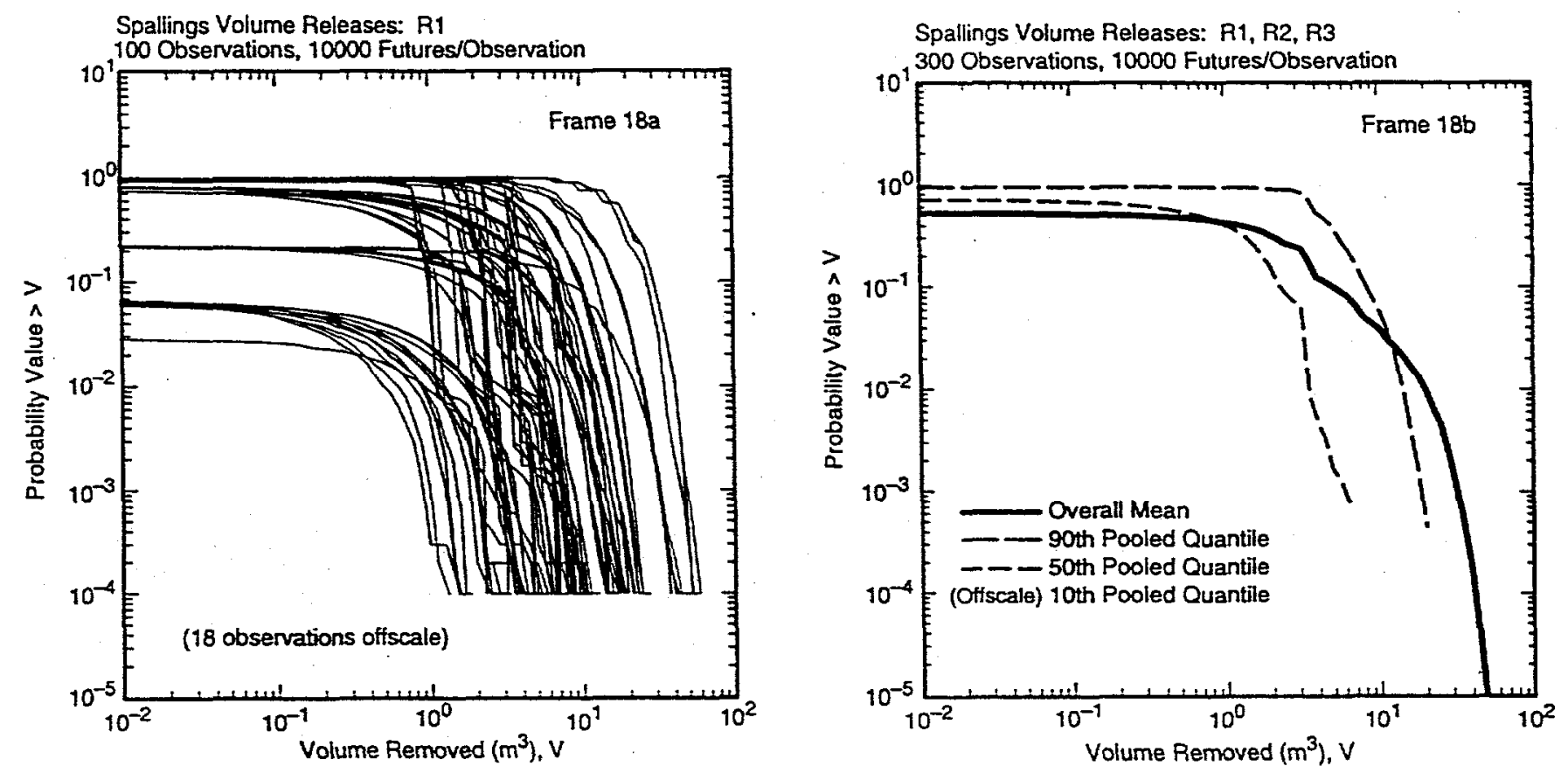

Thi-6342-4987-0

Fig. 18. Distribution of CCDFs for volume of material removed to accessible environment over 10,000 yr due to spallings: (18a) CCDFs for replicate R1, and (18b) mean and percentile curves obtained by pooling replicates R1, R2 and R3. 
Expected Spallings Release: R1, R2, R3

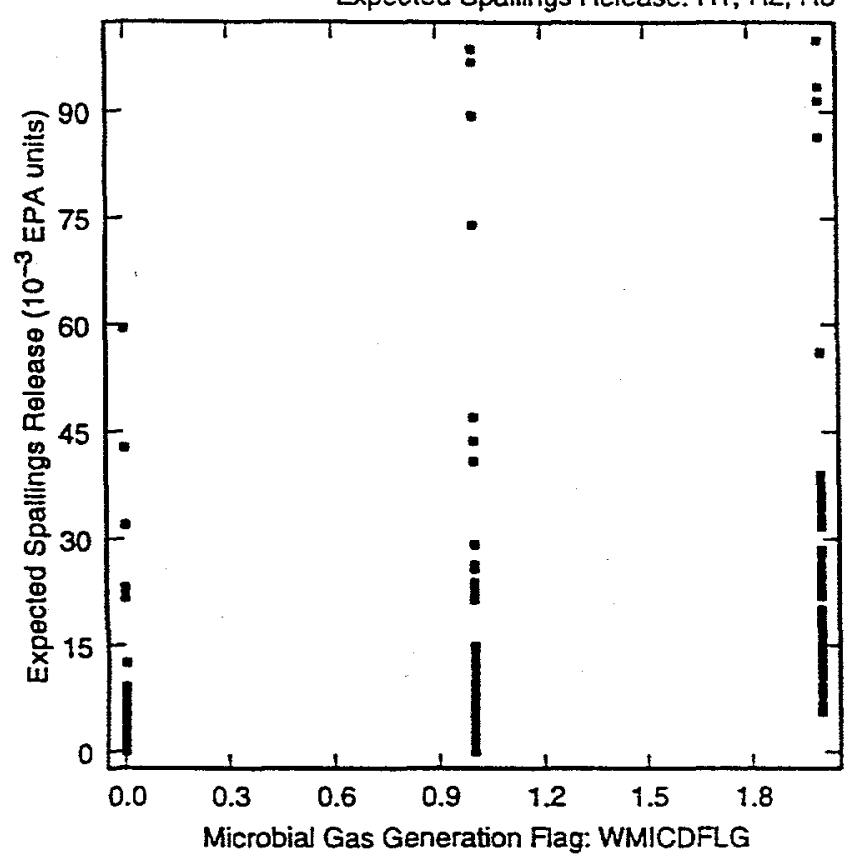

Expected Spallings Release: R1, R2, R3

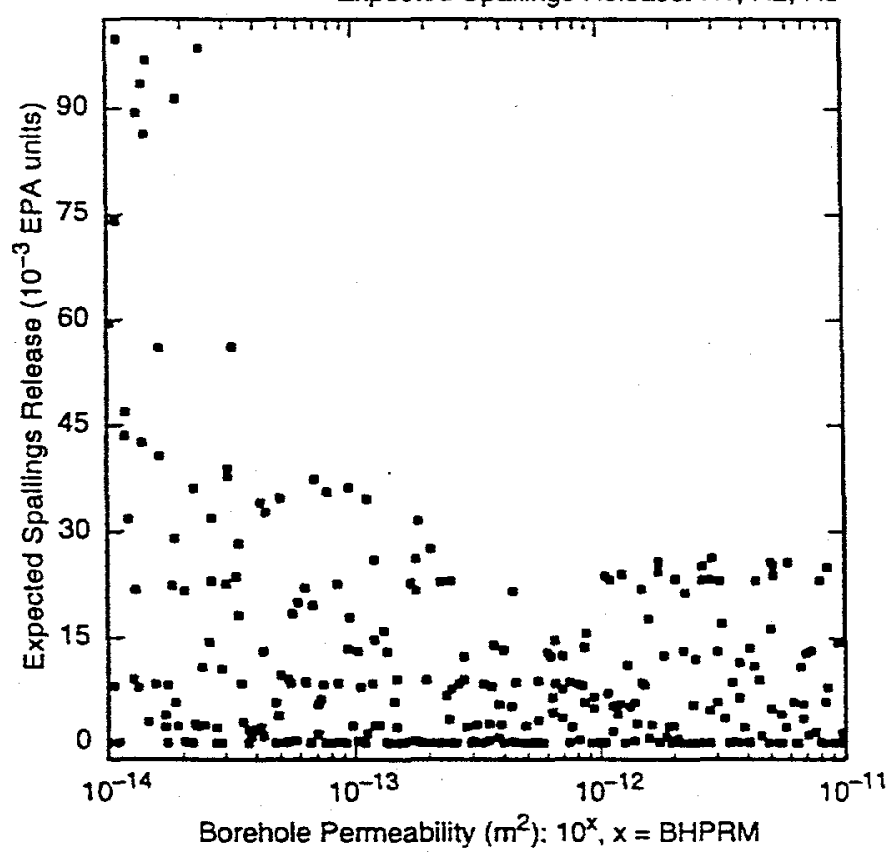

Expected Spallings Release: R1, R2, R3

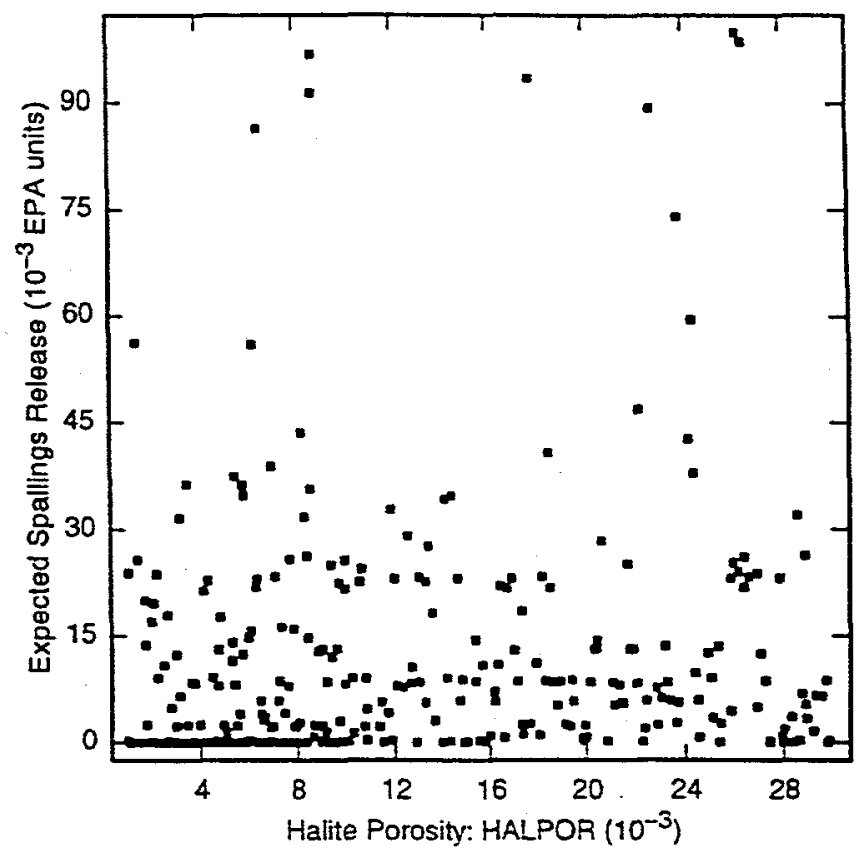

Expected Spallings Release: R1, R2, R3

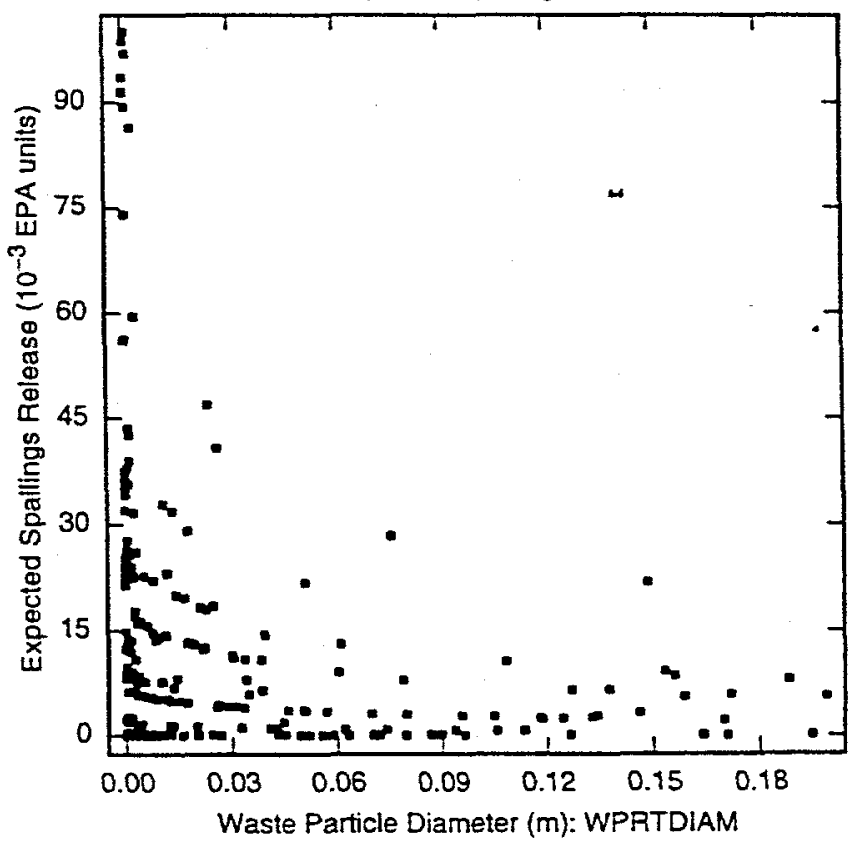

TR1 $6342.5176-0$

Fig. 19. Scatterplots for expected normalized releases associated with individual CCDFs for spallings versus WMICDFLG, HALPOR, BHPRM, and WPRTDIAM. 

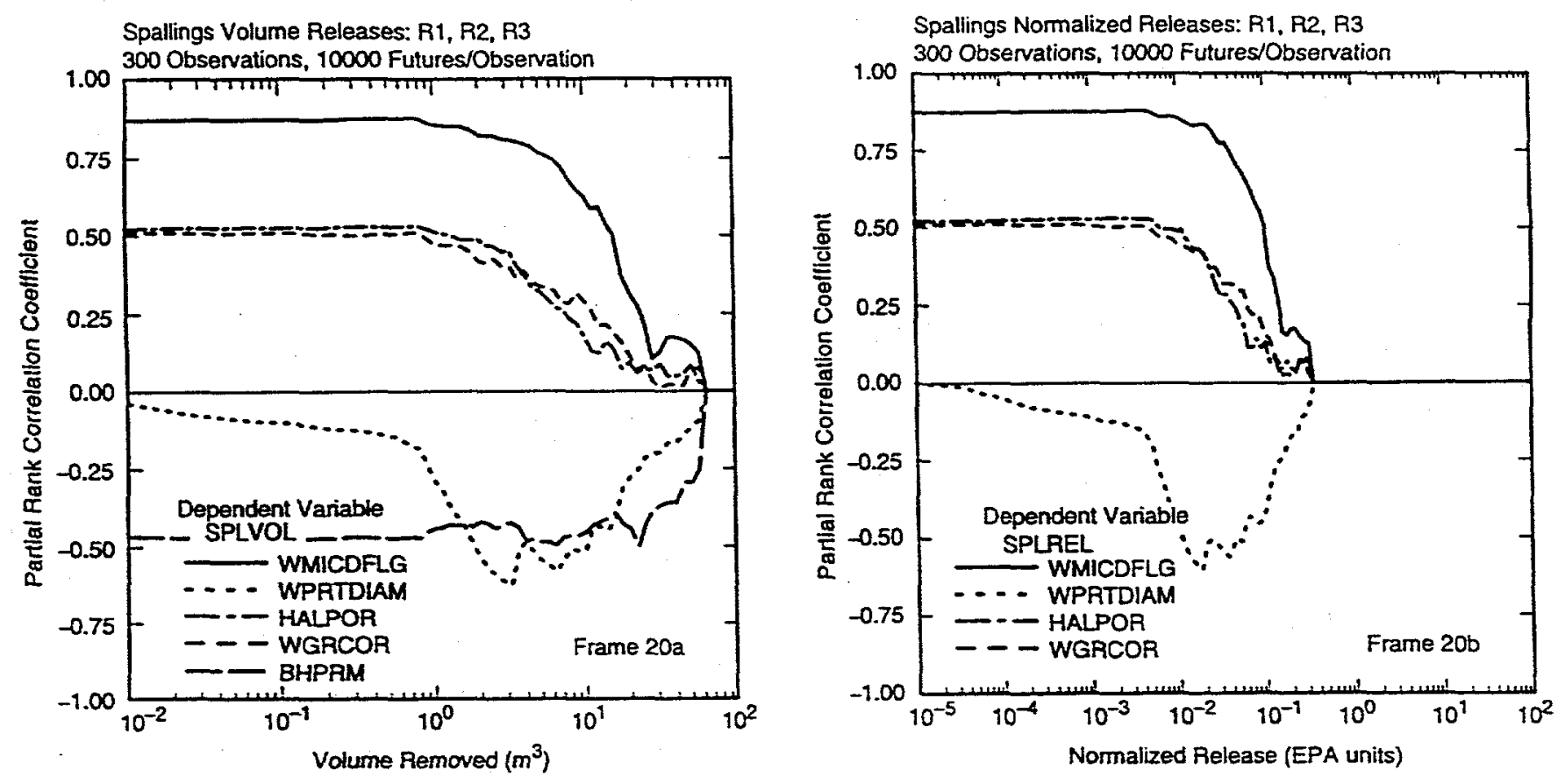

TRI-6342-5iT7-0

Fig. 20. Sensitivity analysis based on PRCCs for CCDFs for volume removed (Frame 20a) and normalized release (Frame 20b) due to spallings.

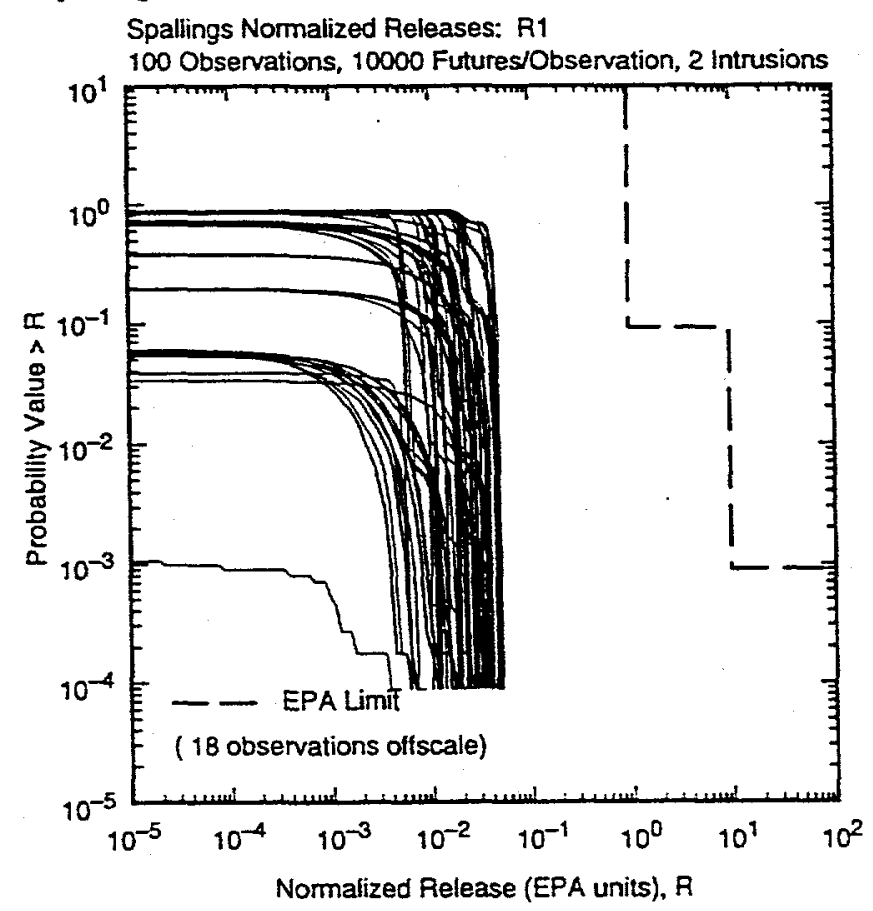

TRI-6342-4988-0a

Fig. 21. Distribution of CCDFs obtained with replicate $R 1$ for normalized release to accessible environment over $10,000 \mathrm{yr}$ due to spallings with the assumption that spalings releases will only take place for the first two drilling intrusions into the repository. 
Table 1. Results Available for Use in CCDF Construction for Cuttings and Cavings Removal

\begin{tabular}{|c|c|}
\hline$\left.\tau_{k}\right)$ & $\begin{array}{l}=\text { concentration }\left(\mathrm{EPA} \text { units } / \mathrm{m}^{3} \text { ) in CH-TRU waste stream } j, j=1,2, \ldots, 569 \text {, at time } \tau_{k} \text {, where } \tau_{k}, k=\right. \\
1,2,3,4,5,6,7,8,9 \text {, corresponds to } 100,125,175,350,1000,3000,5000,7500 \text { and } 10,000 \mathrm{yr} \text {, } \\
\text { respectively. Value: See Table 3, Fig. 3, Ref. } 7 \text {. Source: Refs. } 37-39 .\end{array}$ \\
\hline $\mathrm{CH}(\mathrm{j})$ & $\begin{array}{l}=\text { probability that a randomly sampled drum of } \mathrm{CH} \text {-TRU waste will come from waste stream } j, j=1 \text {, } \\
2, \ldots, 569 \text {. Value: See Table } 3 \text {, Fig. } 3 \text {, Ref. } 7 \text {. Source: Refs. } 37-39 .\end{array}$ \\
\hline $\mathrm{CH}$ & $\begin{array}{l}=\text { area }\left(\mathrm{m}^{2}\right) \text { through } \mathrm{CH}-\mathrm{TRU} \text { waste removed due to cuttings and cavings associated with a single } \\
\text { drilling intrusion. Source: CUTTINGS_S. }\end{array}$ \\
\hline$H_{C H}$ & $\begin{array}{l}=\text { height }(\mathrm{m}) \text { of waste panels used for disposal of CH-TRU waste. Value: } 3.96 \mathrm{~m} \text {. Source: WIPP } \\
\text { design. }\end{array}$ \\
\hline$F_{C H}$ & $\begin{array}{l}=\text { fraction of volume removed by drilling intrusion through CH-TRU waste that is actually waste. } \\
\text { Value: } 0.386=\text { (volume of CH-TRU waste) } / \text { (volume of waste panels) }=\left(1.685 \times 10^{5} \mathrm{~m}^{3} /\right. \\
4.36 \times 10^{5} \mathrm{~m}^{3} \text { ). Source: WIPP design, Ref. } 37 .\end{array}$ \\
\hline$C_{R H}\left(\tau_{k}\right)$ & $\begin{aligned} &= \text { concentration }\left(\mathrm{EPA} \text { units } / \mathrm{m}^{3}\right) \text { in RH-TRU waste at time } \tau_{k} \text {, with } \tau_{k} \text { corresponding to the same } \\
& \text { times used with } C_{C H}\left(j, \tau_{k}\right) \text { for CH-TRU waste. Value: See Fig. } 2 \text {. Source: Refs. } 37-39 .\end{aligned}$ \\
\hline$A_{R H}$ & $\begin{aligned}= & \text { same as } A_{C H} \text { but for RH-TRU waste. Value: } 0.076 \mathrm{~m}^{2}=\pi(\text { drill bit diameter } / 2)^{2}=\pi(0.31115 / 2)^{2} . \\
& \text { Rationale: Little erosion around the drill bit takes place for intrusions through RH-TRU waste. }\end{aligned}$ \\
\hline & $=$ same as $H_{C H}$ but for RH-TRU waste. Value: $0.509 \mathrm{~m}$. Source: Ref. 20. \\
\hline & $\begin{aligned}= & \text { Same as } F_{C H} \text { but for RH-TRU waste. Value: 1. Rationale: Consistent with emplace } \\
\text { procedure for RH-TRU waste and definition of } H_{R H} & \end{aligned}$ \\
\hline
\end{tabular}


Table 2. Results Available for Use in CCDF Construction for Spallings Releases

\begin{tabular}{|c|c|c|}
\hline$C_{C H}\left(\tau_{k}\right)$ & $=$ & $\begin{array}{l}\text { concentration (EPA units } / \mathrm{m}^{3} \text { ) in CH-TRU waste at time } \tau_{k} \text {, where } \tau_{k}, k=1,2, \ldots, 9 \text {, } \\
\text { corresponds to } 100,125,175,350,1000,3000,5000,7500 \text { and } 10,000 \mathrm{yr} \text {, respectively. } \\
\text { See curve "CH-TRU waste within waste panels" in Fig. } 2 \text {. Source: Refs. } 37-39 \text {. }\end{array}$ \\
\hline$V S_{E 0, U}\left(\tau_{k}\right)$ & $=$ & $\begin{array}{l}\text { volume }\left(\mathrm{m}^{3}\right) \text { of original (i.e., uncompacted) material released by a drilling intrusion into a } \\
\text { previously unintruded repository at time } \tau_{k} \text { that encounters CH-TRU waste in an upper } \\
\text { waste panel, where } \tau_{k}, k=1,2, \ldots, 6 \text { corresponds to } 100,350,1000,3000,5000 \text { and } \\
10,000 \mathrm{yr} \text {, respectively. See Fig. } 10 \text {. Source: CUTTINGS_S. }\end{array}$ \\
\hline$V S_{E 0, L}\left(\tau_{k}\right)$ & $=$ & same as $V S_{E 0, U}\left(\tau_{k}\right)$ but for intrusion into a lower waste panel. See Fig. 10. \\
\hline$V S_{E 1, S}\left(\tau_{j}, \Delta \tau_{j k}\right)$ & $=$ & 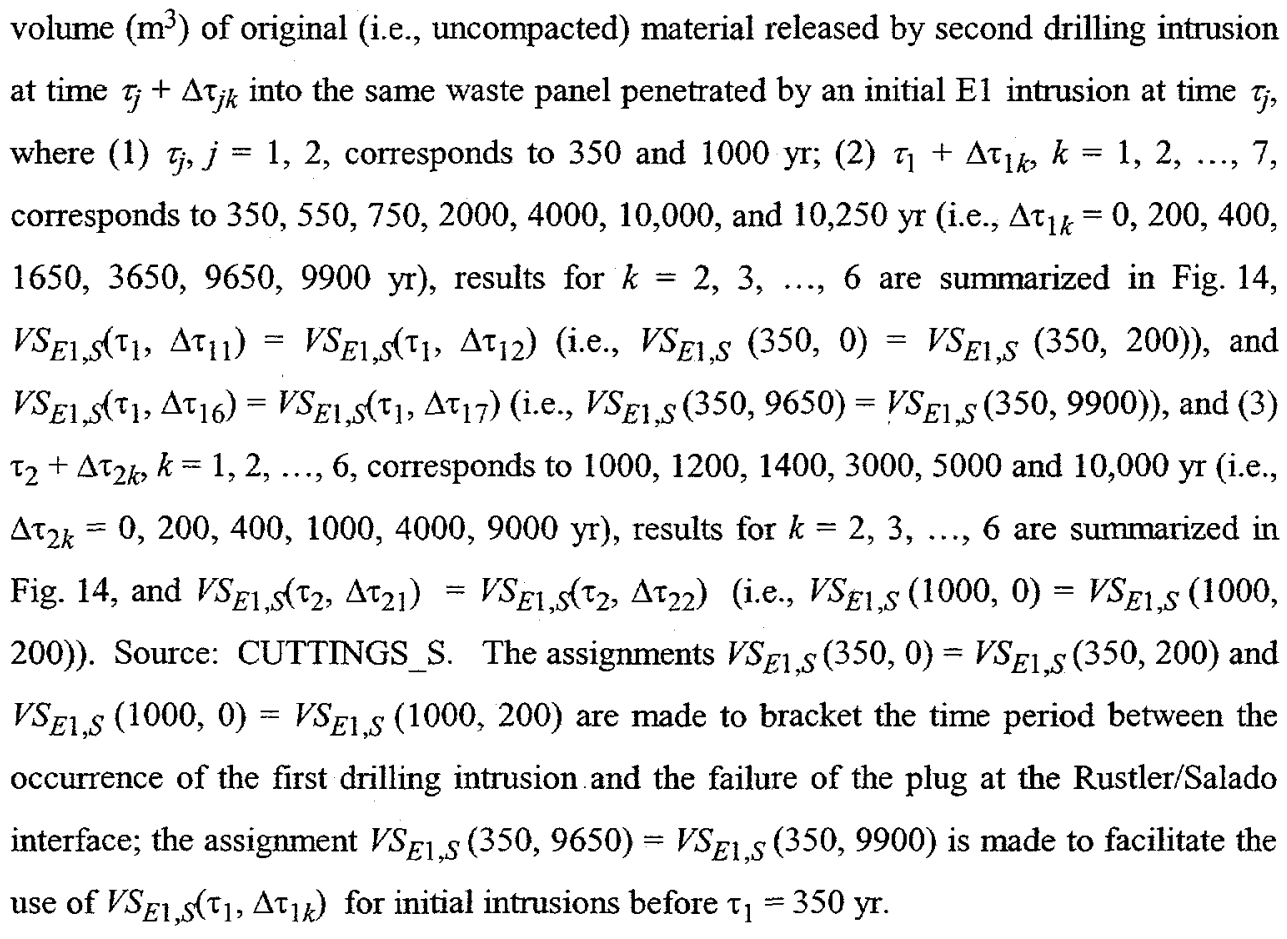 \\
\hline$V S_{E 1, D}\left(\tau_{j}, \Delta \tau_{j k}\right)$ & $=$ & same as $V S_{E 1, S}\left(\tau_{j}, \Delta \tau_{j k}\right)$ but for intrusion into different waste panel. See Fig. 14. \\
\hline$V S_{E 2, S}\left(\tau_{j}, \Delta \tau_{j k}\right)$ & $=$ & same as $V S_{E 1, S}\left(\tau_{j}, \Delta \tau_{j k}\right)$ but for initial E2 intrusion. See Fig. 15 \\
\hline$\Delta l_{j k}$ & - & he as $V S_{E 1, D}\left(\tau_{j}, \Delta \tau_{j k}\right)$ but for initial E2 intrusion. See Fig. 15 \\
\hline
\end{tabular}


Table 3. Determination of Spallings Release $f_{S P}\left(\mathbf{x}_{s t}\right)$ for an Arbitrary Future $\mathbf{x}_{s t}$ of Form in Eq. (30)

Notation:

$n H_{i}=$ number of intrusions prior to intrusion $i$ that penetrate pressurized brine and use plugging pattern 2 (i.e., two discrete plugs)

$n D=$ number of intrusions required to deplete brine pocket (see BPVOL in Table 1, Ref. 8)

$\widetilde{b}_{i}=0$ if intrusion $i$ into (1) nonexcavated area or (2) excavated area and plugging pattern 1 used (i.e., continuous plug)

$=1$ if intrusion $i$ into excavated area, penetrates pressurized brine, plugging pattern 2 used, and $n H_{i} \leq n D$

$=2$ if intrusion $i$ into excavated area and either (1) penetrates pressurized brine, plugging pattern 2 used, and $n H_{i}>n D,(2)$ does not penetrate pressurized brine and plugging pattern 2 used, or (3) plugging pattern 3 used (i.e., three discrete plugs)

Release $r S P_{i}$ for intrusion into nonexcavated area at time $t_{i}: r S P_{i}=0$.

Release $r S P_{i}$ for intrusion into pressurized repository at time $t_{i}$ (i.e., $i=1$ or $\widetilde{b}_{j}=0$ for $j=1,2, \ldots, i-1$ ):

$$
\begin{aligned}
& r S P_{i}=0 \quad \text { if intrusion penetrates RH-TRU waste } \\
& =C_{C H}\left(t_{i}\right)^{\mathrm{a}} V S_{E 0, U}\left(t_{i}\right) \quad \text { if } l_{i} \text { in upper waste panel } \\
& =C_{C H}\left(t_{i}\right) V S_{E 0, L}\left(t_{i}\right) \quad \text { if } l_{i} \text { in lower waste panel. }
\end{aligned}
$$

Release $r S P_{i}$ for intrusion into a depressurized repository at time $t_{i}$ with no $\mathrm{E} 1$ intrusion in first $i-1$ intrusions (i.e., $\widetilde{b}_{k}=0$ for $k=1,2, \ldots, j-1, \widetilde{b}_{j}=2, \widetilde{b}_{k} \neq 1$ for $k=j+1, j+2, \ldots, i-1$ ):

$$
\begin{aligned}
r S P_{i} & =0 & & \text { if intrusion penetrates RH-TRU waste } \\
& =C_{C H}\left(t_{i}\right) V S_{E 2, S}\left(t_{j}, t_{i}-t_{j}\right)^{\mathrm{b}} & & \text { if } l_{j}, l_{i} \text { in same waste panel } \\
& =C_{C H}\left(t_{i}\right) V S_{E 2, D}\left(t_{j}, t_{i}-t_{j}\right) & & \text { if } l_{j}, l_{i} \text { in different waste panels. }
\end{aligned}
$$

Release $r S P_{i}$ for intrusion into a depressurized repository at time $t_{i}$ with first $\mathrm{E} 1$ intrusion at time $t_{j}<t_{i}$ (i.e., $\widetilde{b}_{k} \neq 1$ for $\left.k=1,2, \ldots, j-1, b_{j}=1\right)$ :

$$
\begin{aligned}
r S P_{i} & =0 & & \text { if intrusion penetrates RH-TRU waste } \\
& =C_{C H}\left(t_{i}\right) V S_{E 1, S}\left(t_{j}, t_{i}-t_{j}\right) & & \text { if } l_{j}, l_{i} \text { in same waste panel } \\
& =C_{C H}\left(t_{i}\right) V S_{E 1, D}\left(t_{j}, t_{i}-t_{j}\right) & & \text { if } l_{j}, l_{i} \text { in different waste panels. }
\end{aligned}
$$

Spallings release $f_{S P}\left(\mathbf{x}_{s t}\right)$ :

$$
f_{S P}\left(\mathbf{x}_{s t}\right)=\sum_{i=1}^{n} r S P_{i}
$$

a Here and elsewhere, appearance of an undefined time implies linear interpolation between defined times in Table 2.

b Here and elsewhere, appearance of two undefined times implies two-dimensional linear interpolation between defined times in Table 2. 
Table 4. Stepwise Regression Analyses with Rank-Transformed Data for Expected Volume and Expected Normalized Release Associated with Individual CCDFs for Spallings (see Table 1, Ref. 8, for variable definitions)

\begin{tabular}{|c|l|c|c|l|c|c|}
\cline { 2 - 7 } \multicolumn{1}{c|}{} & \multicolumn{3}{c|}{ Expected Volume } & \multicolumn{2}{c|}{ Expected Normalized Release } \\
\hline Step $^{\mathrm{a}}$ & \multicolumn{1}{c|}{ Variable $^{\mathrm{b}}$} & SRRC & $R^{2}$ & Variable & SRRC & $R^{2}$ \\
\hline 1 & WMICDFLG & 0.70 & 0.51 & WMICDFLG & 0.72 & 0.53 \\
2 & HALPOR & 0.26 & 0.58 & HALPOR & 0.26 & 0.60 \\
3 & WGRCOR & 0.25 & 0.64 & WGRCOR & 0.24 & 0.66 \\
4 & BHPRM & -0.21 & 0.68 & BHPRM & -0.20 & 0.70 \\
5 & WPRTDIAM & -0.19 & 0.72 & WPRTDIAM & -0.19 & 0.73 \\
6 & HALPRM & 0.14 & 0.74 & HALPRM & 0.13 & 0.75 \\
7 & WASTWICK & 0.11 & 0.75 & WASTWICK & 0.11 & 0.76 \\
8 & ANHPRM & 0.10 & 0.76 & ANHPRM & 0.10 & 0.77 \\
\hline
\end{tabular}

a Steps in stepwise regression analysis.

b Variables listed in order of selection in regression analysis with $A N H C O M P$ and HALCOMP excluded from entry into regression model.

c Standardized rank regression coefficients in final regression model.

d Cumulative $R^{2}$ value with entry of each variable into regression model. 